Presented at the Annual AIME 1977

Meeting, Atlanta, GA, March 6-10, 1977;

also Submitted to Metallurgical

$L B L-6092$

Transactions.

\title{
INTERRELATIONS OF COMPOSITIONS, TRANSFORMATION KINETICS, MORPHOLOGY, AND MECHANICAL PROPERTIES OF ALLOY STEELS
}

Earl R. Parker



and

की $10 \%$

March 1977

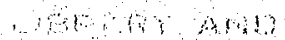

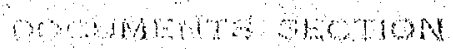

Prepared for the U. S. Energy Research and

Development Administration under Contract W-7405-ENG-48

\section{For Reference}

Not to be taken from this room







\title{
$0+4,4+1,1+3$ \\ $L B L-6092$
}

\author{
INTERRELATIONS OF COMPOSTTTONS, \\ TRANSFORMATTON KINETICS, MORPHOLOGY, AND \\ MECHANTCAL PROPERTIES OF ALLOY STEELS
}

by

Ear1 R. Parker

ABSTRACT

The strong influence of the fine-scale microstructural features on mechanical properties has become increasingly evident during the past decade. This is particularly true for fracture toughness of quenched and tempered alloy steels. Large differences in microstructure can be produced by isothermal, rather than athermal, treatments in the bainite and upper martensite temperature ranges. The kinetics of transformation, as well as the kinds and volume fractions of transformation products can be varied over wide ranges by relatively small changes in chemical composition. The effects of the common alloying elenents on transformation kinetics, both separately and in various combinations were determined experimental1y. The synergistic effects of individual elements added as pairs of elements were not predictable from a knowledge of the effects of the individual elements. Isothermal treatments, coupled with variations in the kinds and anounts of alloying elements, produced different morphologies, compositions, and volume fractions of the transformation products. The effects of such microstructural differences on tensile properties, Eracture toughness, and fatigue characteristics were evaluated. Beneficial effects were found, such as substantial increases in fracture coughness, with small changes in alloy content or with heat treatments that differed from those conventionally used. 

INTRODUCTION

Investigations of the time and temperature dependence of austenite decomposition in steels began in the nineteen-twenties, with the first comprehensive report appearing in the literature in $1930^{(1)}$. The pioneering research of Bain and his coworkers led to the discovery of the bainite transformation, which was a principal topic of interest in the research discussed herein. This reaction is much more complex than the austenite-pearlite transformation. It consists of at least two different reactions - the upper and lower bainite transformations. The nature of these reactions and the morphology of the transformation products have been the subject of many investigations $(1-7)$.

Steels are generally heat treated in one of two ways, by slow cooling or by quenching and tempering. Heat treatments producing transformations in the bainite temperature range have not found widespread use in commercial applications, partly because of the practical difficulties of controling such reactions, and to some extent because of the uncertainties associated with optimizing mechanical properties by such treatments. However, a number of advanced technological applications require improved properties over those attainable with commercial steels and conventional heat treatments. There are indications from published research that enhancement of properties, particularly fracture toughness, might be substantially improved by unusual heat treating procedures, and by minor modifications of the chemical compositions of widely used steels, such as AISI 4340. Extensive investigations have shown that a wide variety of microstructures can be produced through controlled austente decomposition in the bainite temperature range ${ }^{(8-11)}$ and some of these structures should provide unusual combinations of strength and toughness. The present research 
was undertaken with the intent of evaluating the influence on mechanical properties of the fine-scale microstructural features produced by transformations in the bainite temperature range. Properties of quenched and tempered steels are included for comparison. The investigations included a brief study of tempering kinetics of maxtensite in order to clarify the observation that some low alloy steels, when oil quenched rapidly enough to produce 100 percent martensite, were tough and somewhat ductile, instead of extremely brittle as is normally expected for a fully quenched 0.4 percent carbon steel. 


\section{KINETICS OF MARTENSTTE TEMPERTNG}

One of the first points that arose in the investigations was the question, why do one-half-inch thick fxacture toughness specimens of AISI 4340, when tested in the as-oil-quenched condition, behave in a relatively ductile manner when broken? Such specimens have $\mathrm{K}_{\mathrm{IC}}$ values of $40 \mathrm{Ksi} / \mathrm{ins} ., 7$ or more foot pounds Charpy $V$-notch energy, and elongations in tensile tests of almost 10 percent. Also, the fracture surfaces were of the quasi-cleavage and dimpled rupture types and did not exhibit the brittle characteristics of a true martensite. End quenched hardenability tests of this steel jndicated that the centers of oil-quenched plate specimens up to one inch in thickness should be 100 percent martensitic, and curves obtained with thermocouples located at the center plane of one-half-inch thick specimens clearly showed that the cooling rates during quenching were fast enough to prevent the formation of ferrite, pearlite, or bainite. It is well known that true nartensite (with all of the carbon trapped in the form of a supersaturated solid solution) in a 0.4 percent carbon steel is extremely britcle. How then, could the relatively high ductility exhibited by the fracture coughness, charpy and tensile specimens be explained? The probably answer was that autotempexing of the martensite was occurring during the very short the period when the specimens were in the temperature range between the $M_{\mathrm{S}}$ and room temperature. Some simple experinents were then made to explore the effect of quenching rate. Flat pieces of different thickness were oil quenched from $850^{\circ} \mathrm{C}$, and a surprising result was obtained. Specinens of AISI 4340 steel as thin as 0.030 inch could be bent $90^{\circ}$ without breaking. It was found necessary to quench specimens of this thickness in iced brine before they would exhibit the characteristic brittleness of martensite in the asmquenched condition, i.e., virtually zero plastic deformation before fracture. These simple experiments showed clearly that autotempering can occur 
even in a few seconds below the $\mathrm{M}_{\mathrm{S}}$ temperature $\left(300^{\circ} \mathrm{C}\right)$. Subsequently transmission electron microscope studies revealed that epsilon carbide had precipitated during quenching in the one-half-inch thick fracture toughness specimens. The type of structure produced is illustrated by the electron micrograph shown in Fig. 1. Even the 0.030-inch thick bend test specimens, which cooled much faster than the half-inch thick fracture toughness specimen, during oil quenchings, was autotempered. A study of autotempering rates in this high hardenability steel seemed to be needed to provide additional insight into autotempering kinetics.

There seemed to be no simple way to measure the precipitation rate of carbon in martensite during direct quenching to room temperature, so it was considered expedient to obtain some quantitative data on carbon precipitation kinetics In martensite at various constant temperatures between the $\mathrm{M}_{\mathrm{s}}$ and room temperaure. The experimental procedure commonly used by researchers for an investigation of this type is to quench very small pieces of steel extremely rapidly to retain the carbon in solution $(12-15)$. Upon heating the quenched specimens at various temperatures, the change in electrical resistance, measured as a function of time, provides a measure of carbon precipitation kinetics. Such measurements have shown that the precipitation process begins without a detectable incubation period $(13,16,17)$ and, at a constant temperature, proceeds at a rate which diminishes rapidly with increasing time. Resistance measurements in much of the earlier work werestarted about one minute after the test specimens reached the cempering remperature, although some of the measurements were made within about ten seconds after reheating specimens to the reaction temperature. It was evident that more information was needed about tempering rates in time periods of a few seconds. Consequently, experiments were performed ${ }^{(18)}$ which provided additional data for shorter time periods. 


\section{1}

Tempering occurs in several well-recognized stages, with the first stage consisting of the formation of discontinuous precipitates $(16,19,20)$ of metratuble transition carbides. The second and ihird atages comprise the


("The later two stages with be discussed in detait in later sections.) prior to the onset of the frot etage, there is an inttal stage in which carbon segrew

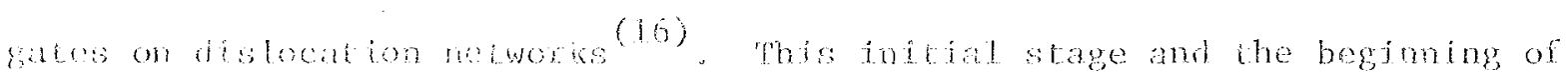
Whe firse siagn are the ones involver th abotemeeng. The kinetics of anty tempertag raw ions have ben scudied by various nethods $(21-33)$ and the rowlts have been studied by many investigators, but no entirely satisfactory andel for the enty tompong reaction has evolved. Witson and owen (33), using: 1.0 percent carton steels with chromium contents ranging from 0 to 2.85 percons, measured initial tempering rates in the temperature range 50 to $196{ }^{\circ} \mathrm{C}$ by the clectical resisivity method. They found large changes in resistance within the first teo seconds at temperatures above $120^{\circ} \mathrm{C}$. No end moint state was reached in their experiments, so they were unable to express the resistance changes in terms of peccentage of the maximum change that would occur when all of the carbon had prectpitated. In the present study ${ }^{(18)}$ higher tempering, temperatures were employad as we 11 as low ones, and initial tempering rate data for fully temperat steels were obcaned at and above $240{ }^{\circ} \mathrm{C}$. Reasonable ostinatos of mies at cenperatures as low as $100^{\circ} \mathrm{g}$ were also obtained. The

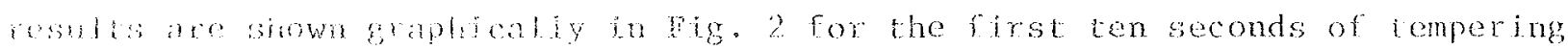

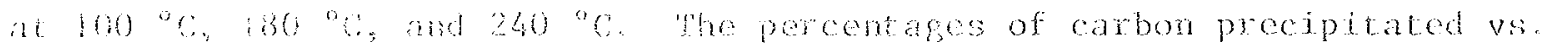

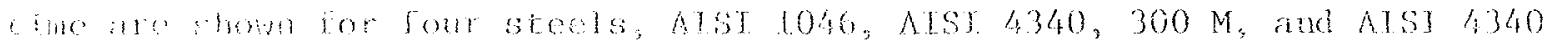

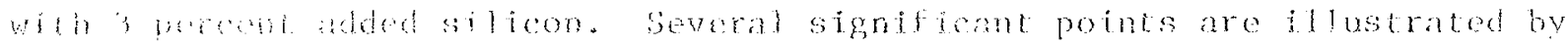

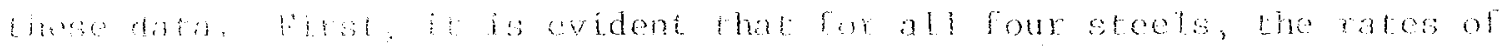
anpering are extremely high at cemperatures of $240{ }^{\circ} \mathrm{C}$, with approsimately 50

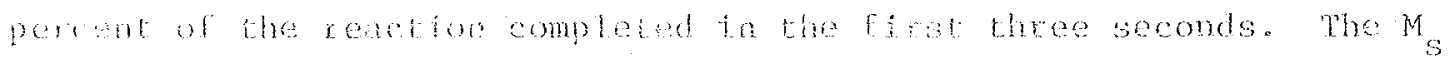


temperatures of these steels are 50 to 100 degrees above this temperature, and cooling curves for the midplane of one-half-inch thick oil-quenched fracture toughness specimens show that the time required for the temperature to decrease from $300{ }^{\circ} \mathrm{C}$ to $200{ }^{\circ} \mathrm{C}$ is approximately 10 seconds. About 90 percent of the austenite transforms to martensite in this temperature range, so there is ample time for extensive autotempering to occur. The high toughness and somewhat ductile nature of the fractures obtained with fracture toughness specimens can therefore be understood. 


\section{ISOTHERMAL TRANSFORMATION STUDIES AND BAINITE REACTIONS}

Many investigators have studied the kinetics of formation of bainite and the morphologies of the structures produced, but adequate explanations of the experimental observations are, in many respects, still lacking, as is a quantitative general theory of austenite decomposition in the bainite temperature range. The effects of combinations of alloying elements on bainite transformation kinetics are not simply additive, and sufficient data are not available to evaluate the synergistic effects of the commonly used elements.

It is evident from published data that synergistic effects can be large and complex. If the bainite reaction could be quantitatively evaluated, it might then become possible to predict chemical compositions and thermal histories that would produce steels with the microstructures needed for optimization of mechanical properties. This is not possible with available information, but research is curxently in progress which will provide additional time-temperature data to help fill the information gap. Examples of some of the work in progress are discussed in the following paragraph.

Dilatometric experiments were performed on seven Fe-C-X ternary systems (where $\mathrm{X}=\mathrm{Mo}, \mathrm{Cr}, \mathrm{Mn}, \mathrm{A} 1, \mathrm{Si}, \mathrm{Co})$ at different alloy concentrations (34). Additional experiments that include combinations of the $\mathrm{X}$ components are currently in progress in order to provide data for the study of interactive effects. Results to date indicate that $\mathrm{Mn}, \mathrm{Ni}, \mathrm{Cr}$, and $\mathrm{Al}$ retard the bainite reaction, Co accelerates the reaction, as does Mo to a lesser degree; Si has little effect. Combined alloy additions have effects on reaction start times that are not predictable from the effects of the individual elements. 
The ranges of compositions of the elements investigated were $0.14-0.4 \mathrm{C}$, $1.0 \mathrm{Cr}, 1.0-2.0 \mathrm{Ni}, 1.7-2.1 \mathrm{Mn}, 1.0-3.0 \mathrm{Si}, 1.0-2.0 \mathrm{~A} 1,0.5-1.0 \mathrm{Co}$, and 0.3-0.5Mo, all in weight percent. Phosphorous and sulfur were less than 0.005 percent. Cooling rates from the austenitizing temperature to the bainite range were between $150{ }^{\circ} \mathrm{C}$ and $450{ }^{\circ} \mathrm{C}$ per second. In a 11 cases, the cooling was fast enough to avoid the formation of ferrice and pearlite. Specimens were held at constant temperature in the bainite range until the reaction was completed. A11 specimens wexe subsequently checked for retained austenite, which was found to be less than five percent, with the exception of the three percent silicon alloy which contained seven percent.

It is well known that there are two major forms of bainite, upper and lower, and that there are easily distinguishable microstructural differences between the two forms. In upper bainite, the carbides are often observed to form elongated particles between the bainicic ferrite grains. In lower bainite, the carbides tend to precipitate within the ferrite grains at an inclined angle to the major growth direction of the ferrite. The two reactions also exhibit diferences in kinetlcs of formation (35-39), although both upper and lower bainite form by a shear mechanism $(39-42)$.

Pickexing made a systematic investigation of bainitic transformations in both hypoeutectoid and hypereutectoid steels which contained Mo, B, and Cr (43) In addition to studying microstructural factors, he confirmed the fact that the temperature below which lower bainite, rather than upper bainite, formed was dependent upon the carbon content, increasing from $450{ }^{\circ} \mathrm{C}$ to $550{ }^{\circ} \mathrm{C}$ with increasing carbon, but dropping abruptly to $350^{\circ} \mathrm{C}$ for all hypereutectoid steels. For hypoeutectoid steels, the line shown in the figure separating upper from lower bainite regions follows the line indicating the saturation concentration 
of carbon in austenite. The fine scale microstructural details in either form of bainite are dependent upon the temperature of the transformation as wel1 as upon the carbon content of the stee1. Hence the control of microstructure for the purpose of optimizing mechanical properties requires a deep insight into the interactive nature of these parameters and upon other factors that will be considered in subsequent sections.

The metallic elements commonly used in heat-treatable, low-alloy steels (Mn, Si, Cr, Ni, Mo, V) alter both the eutectoid composition and the eutectoid temperature. The saturation concentration of carbon in austenite at various temperatures: plays a major role in detemining the temperature for hypoeutectoid steels above which lower bainite does not form. An example of how the temperature-carbon content line can be shifted by varying the mix of metallic alloying elements is shown in Fig. 4. Pickering"s steels were of two types, 0.5 Mo plus boron and 1.0Cr, 0.5Mo, plus boron. The other steels used for determining the lower line were $0.3-0.5 \mathrm{Mo}$, or $1.0-2.0 \mathrm{Ni}$, or combinations of $\mathrm{Ni}, \mathrm{Cr}$, and Mo ${ }^{(34)}$. As mentioned earlier, the cemperature of transformation for either upper or lower bainite has a major influence on the fine scale microstructural features, and hence can have a major effect on mechanical properties. It has been repeatedly shown that the lower the transformation temperature, the higher will be the yield and tensile strengths. For example, pickering (43) found that a linear relationship exists between the tensile strength and the transformation temperature. He reported tensile strengths for a number of bainitic steels ranging from $175 \mathrm{ksi}\left(1200 \mathrm{mN} / \mathrm{m}^{2}\right)$ for steels transformed at $430^{\circ} \mathrm{C}$ to $78 \mathrm{ksi}\left(534 \mathrm{MN} / \mathrm{m}^{2}\right)$ for steels at $650{ }^{\circ} \mathrm{C}$. The range of transformation temperatures for lower bainite is strongly dependent on chemical composition, and thus the range of properties is correspondingly dependent upon alloy chemistry. 
The notch toughness of steels having upper bainitic structures, whether indicated by $K_{I c}$ values or by the temperature of transition from ductile to brittle fracture in impact tests on notched bars, are inferior to steels of the same strength having lower bainitic microstructures. For example, in Pickering"s work (43), a steel with an upper bainitic structure and a tensile strength of $134 \mathrm{ksi}\left(124 \mathrm{MN} / \mathrm{m}^{2}\right)$ had an impact transition tenperature of $75{ }^{\circ} \mathrm{C}$, whereas the same steel with a lowerbainitic structure and a tensile strength of $145 \mathrm{ksi}\left(1000 \mathrm{MN} / \mathrm{m}^{2}\right)$ had an impact transition temperature of $20{ }^{\circ} \mathrm{C}$. It is abundantly clear from evidence in the literature that excellent combinations of mechanical properties can be obtained with steels having lower bainitic microstructures. However, in practical applications, it is not always possible to avoid the formation of upper bainite, and this complicates the problem of optimizing properties. Continuous cooling of thick plates often imposes temperature-time histories that produce microstructures which are predominantly of the upper bainite type. However, much can be done to control the structures formed by an upper bainite reaction. In a later section some examples will be shown of how combinations of chemical composition and controlled slow cooling through the upper bainite cemperature range can produce steels with excellent fracture toughness, along with yield and tensile strengths that are adequately high for satisfactory use in many rechnological applications.

The practice of using either isothermal (44) or continuous cooling (45) transformation-time curves as a basis for devising new alloys is fraught with difficulties. There are four main decomposition reactions of austenite in melium carbon steels, with the tcansformation products and approximats" temperature ranges of formation being - ferrite and pearlite (about $750{ }^{\circ} \mathrm{C}$ to $600{ }^{\circ} \mathrm{C}$ ), upper bainite (about $600{ }^{\circ} \mathrm{C}$ to $400{ }^{\circ} \mathrm{C}$ ), Jower bainite (about $550{ }^{\circ} \mathrm{C}$ to below the $\left.\mathrm{M}_{\mathrm{S}}\right)$, and martensite $\left(\mathrm{M}_{\mathrm{S}}\right.$ about $300{ }^{\circ} \mathrm{C}$ for 0.4 percent $\left.\mathrm{C}\right)$. 


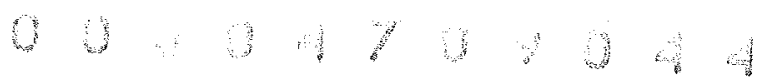

Each of the three highest temperature reactions are time-dependent and ideally each should exhibit a characteristic c-curve for the time-temperature relationship. In the pearlite temperature range the expected kinetic behavior is observed. However, two reaction curves often overlap and umusual shapes of time-temperature curves result. Also, the lower bainite curve frequently extends below the $M_{S}$, and its shape is influenced by the plastic strains produced in the austenite that remains after some martensite forms. This transformation-induced plastic flow accelerates the lower bainite reaction. Some typical examples of transformation-time curves are shown in Figs. 5, 6, and 7. In Fig. 5, the isothermal time-temperature austenite decomposition curves obtained by dilatometry are shown for a steel containing 0.17 percent carbon and one percent of chromium. This diagram is relatively simple and easily understood. Both bainite reaction ranges are visible in this figure, wh the upper bainite knee being at about $475^{\circ} \mathrm{C}$ and the lower bainite knee being at about $325^{\circ} \mathrm{C}$, just above the $M_{s}$ temperature. Fig. 6 shows isothermal transfomation data obtained by a magnetic permeability technique ${ }^{(46)}$ for an AISI 4340 steel. With the magnetic method, it was possible to follow the bainite reaction below the $M_{\text {s }}$ temperature with a reasonably high degree of accuracy. The lower bainite knee was found to exist below the $\mathrm{M}_{\mathrm{s}}$ temperature, with the reaction-staxt times found to be shorter than would normally be expected in the absence of a martensite transformation.

The interactive effects of alloying elements are different for the two bainite reactions. This is illustrated in Fig. 7, which shows the start and ending (95\%) curves for three stee1s, one containing 0.29 percent carbon and one percent of nickel, another steel containing 0.29 percent carbon and one percent of chromium, and another steel with the same carbon content but containing one

percent each of nickel and chromium (34). Different effects of alloying elements $-11-$ 
are to be expected for the upper and lower bainite transformations because of the we11-known differences in the nature of the two reactions. Available data clearly indicate that interactive effects of alloying elements on bainite transformations are so complicated that it is unreasonable to expect that such effects can be expressed in simple arithmetic terms. Austenite decomposition kinetics are affected by numerous factors, including chemical free energy changes produced by alloy combinations, influence of alloying elements on the solubility of carbon in austenite, morphology and type of carbides that precipitate, spacing between carbide particles, changes occurring in the composition of the austenite as ferrite forms in upper bainite, effects of dislocations created by volume changes that occur during phases transw formations, and probably other factors that are not as obvious as those stated above. In spite of the obvious difficulty of sorting out and evaluating all of the influential factors, it is hopedthat eventually a clearer understanding of the austenite-bainite reactions will evolve.

Reports of many investigations concerned with the microstructural and kinetic aspects of the bainite reactions have appeared in the 1iterature $(7,47-51)$. Kinetic differences between the uppex and lower bainite reactions cannot be clarified by isothermal decomposition data, which reflect the volume percent of austenite decomposed as functions of time and temperature. Attempts to secure activation energies associated with these reactions have been fruitless because a number of temperacure dependent factors contribute to the kinetics of the bulk reaction processes. This point is illustrated by Fig. 8 , where the reciprocal of the reaction temperature is plotted as a function of the negative natural $10 \mathrm{~g}$ of the cime for various "equivalent reaction states" for the $0.29 \mathrm{C}, 1.0 \mathrm{Ni}$ steel. The futility of attempting to determine an activation energy for either upper or lower bainite is immediacely obvious. 
The slopes of the curves for both reactions are continuously variable and can be either positive or negative, depending upon the temperature selected. In order to obtain valid data for activation energy calculations it is necessary to measure the isothermal growth rates of individual bainite plates, not the bulk transformation rates. A number of such experiments have been made by investigators employing hot stage microscopy $(7,41,52,53)$. Both types of bainite plates were found to grow at slow temperature-dependent rates. Lower bainite was observed to grow as individual plates which increased in both length and thickness with time. Upper bainite developed as groups of closely spaced parallel needles with rectangular cross-sections $(7,54)$. The needles increased in length at uniform velocities but were limited in thickness by the proximity of neighboring needles. The growth rates for both types of bainite increased with increasing temperature and the semilog plots of growth rate versus the reciprocal of temperature could be represented by two distinctly separate straight lines ${ }^{(7)}$. From the slopes of these lines, the activation. energies were estimated to be approximately 20,000 calories per mole for lower bainite (a value consistent with the activation energy for carbon diffusion) and 1000 to 9000 calories per mole for upper bainite, depending on the carbon content. The low activation energy values for upper bainite have no simple meaning. The upper bainite reaction is complex. Ferrite forms as a separate phase, with the consequent concentration of carbon in the remaining austenite. Upper bainite is characterized by the presence of parallel ferrite laths exhibiting bigh dislocation densities $(55-5 \%)$. The laths are close-packed and have been observed to be about $0.6 \mu \mathrm{m}$ wide when examined by transmission electron microscopy. When examined by optical microscopy, the bainite regions appear to be about 3 um wide. These wider regions consist of a number of substructural units, normally unresolvable by optical microscopy. 
The subunits in a growing upper bainite region do not all grow at the same rate ${ }^{(57)}$. Aaronson ${ }^{(58)}$ has suggested that the lath-like structure of upper bainite results from sympathetic nucleation of the subunits. The subunits nucleate along the side of other units that apparently have nearly stopped growing. This discontinuous type of growth results in the formation of subunits that have 1imited lengths, usual1y ranging between $10 \mu \mathrm{m}$ and $15 \mu \mathrm{m}$. The diffusion model for upper bainite is based upon the growth rate of individual bainite regions within an aggregate, as observed with hot-stage optical microscopy. However, the discontinous growth of groups of subunits is not resolvable in such experiments, and the measurements thus reflect the bulk growth rate, not the growth rate of the individual subunits. The theoretical growth rates of the subunits are an order of magnitude higher than the observed bulk rates. The low values of activation energies for the growth of upper bainite, i.e., 1000 to 9000 calories per mole ${ }^{(7)}$, do not reflect the kinetics of a diffusional process. Nucleation appears to be the rate controlling step of the growth process ${ }^{(57)}$.

Another complication associated with upper bainite formation is that upper bainite will not form above a well-defined temperature, designated $\mathrm{B}_{\mathrm{S}}$ ? which is generally below the pearlite formation range; $B_{S}$ is dependent upon the carbon content of the austenite, being lower for higher carbon concentrations. Between the $B_{S}$ and a lower temperature, $B_{f}$, below which upper bainite does not form, the amount of austenite that transforms to bainite is temperature-dependent, increasing from zero just above the $B_{S}$, to a maximum at $B_{f}(59)$. At the higher temperatures within this range, carbon is rejected as ferrite forms and the carbon concentrates in the remaining austenite. At 
a constant temperature, the carbon concentration increases in the austenite until the $B_{s}$ of the carbon-enriched austenite reaches the reaction temperature; when this occurs, the reaction ceases.

In investigations that have been made of growth rates in the lower bainite temperature range, the experimental results revealed a temperature dependence that was consistent with a carbon diffusion model, but the observed growth rates were an order of magnitude lower than predicted. This led oblak and Hehemann $(57)$ to investigate the possibility that lower bainite, like upper bainite, grows by repeated nucleation of subunits. They showed evidence that this type of growth does occur in lower bainite plates, but there are still differences of opinion about the detailed processes of growth.

The size, distribution, and nature of the carbide particles, in both upper and lower bainite control, to a large degree, the mechanical properties of steels with bainitic microstructures. In regard to the origin of carbides in upper bainite, it is clear that most of the carbides in hypoeutectoid steels precipitate as $\mathrm{Fe}_{3} \mathrm{C}$ from the residual carbon-enriched austente films that form between the ferrite laths. In lower bainite, the carbon-enriched austenite is absent, and the carbides precipitate uniformly in the ferrite 1aths. This condition strongly indicates that the carbides precipitate almost exclusively from supersacurated ferrite.

The crystallographic relationships between the ferrite and carbides also indicates that the carbide forms from enriched austenite for upper bainite and from supersaturated ferrite in lower bainite $(56,60,61)$. 
The morphology of the carbides differs markedly in upper and lower bainite, as shown in Fig. 9. These electron micrographs, taken from the work of Thomas (61), show the characteristic elongated stringers of $\mathrm{Fe}_{3} \mathrm{C}$ between the upper bainite ferrite laths. The fracture toughness of steels having this kind of microstructure is low compared with steels having the lower bainitic microstructure illustrated in Fig. 1 which is free from interlath carbides. Epsilon carbide precipitates uniformly in lower bainite, with the crystallographic relationship between the epsilon carbide and the bainitic ferrite being $(0001) \varepsilon||(011) \alpha$ and $[1011] \varepsilon||[101] \alpha^{(61)}$. The epsilon carbide, whether produced by autotempering of martensite or by a lower bainite reaction, only forms at low temperatures. It is metastable and dissolves when $\mathrm{Fe}_{3} \mathrm{C}$ forms at higher tempering temperatures. The $\mathrm{Fe}_{3} \mathrm{C}$ particles are similar in appearance to epsilon carbide, but they can be identified by selected area diffraction and trace analysis of electron micrographs which show that they form on $\{110\}$ alpha planes.

Epsiton carbide is a semicoherent precipitate which imparts a highly desirable combination of high strength and high fracture toughness to bainitic steels. It is therefore a desirable microconstituent. Cementite particles provide strength, but of ten cause a marked lowering of toughness, particularly when the $\mathrm{Fe}_{3} \mathrm{C}$ is in the form of interlath sheets as shown in Fig. 9, or even when the particles are large and spheroidal. These adverse effects are discussed in detail in subsequent sections relating fracture toughness properties to microstructure.

Because lower bainite containing epsilon carbide has unusually good mechanical properties, it is important to consider the fact that the stability of epsilon 
carbide relative to cementite can be altered by additions of silicon $(49,62)$. The presence of silicon in amounts exceeding about one weight percent retards significantly the rate of precipitation of cementite in ferrite, but silicon has only a minor effect on the formation of epsilon carbide which precipitates at an extremely rapid rate, as was illustrated in Fig. 2. Silicon also suppresses the formation of cementite in upper bainite ${ }^{(57)}$, enhancing the concentration of carbon in the untransformed austenite films that form between the ferrite laths. The precipitation of cementite from the austenite, a process wich embrittles steels, is retarded by the presence of a few percent of silicon. The effect of silicon is highly beneficial, not only in bainitic steels, but also in tempered maxtensitic steels ${ }^{(63)}$ which frequently contain retained austenite as films between the martensite laths. In quenched and tempered steels with normal low silicon contents, the retained austenite, which is supersaturated with respect to carbon, decomposes during tempering in the range of $200{ }^{\circ} \mathrm{C}$ to $370{ }^{\circ} \mathrm{C}\left(400{ }^{\circ} \mathrm{F}\right.$ to $\left.700{ }^{\circ} \mathrm{F}\right)$ and cementite films form. This causes a sharp decrease in toughness which is referred to as tempered martensite embrittlement $(64-67)$. Several percent of silicon prevents this embrittlement because it retards the formation of cementite. The fine-scale microstructural features described above have marked effects on mechanical properties. These effects are discussed in the next section. 
EFFECTS OF MICROSTRUCTURAL FEATURES ON MECHANTCAL PROPERTTES

Several kinds of mechanical property tests were performed to evaluate the effects of the various types of fine-scale microstructure that can be produced by altering the chemical compositions or thermal histories of alloy steels. The properties measured were conventional tensile, fracture toughness ${ }^{(68)}$, Charpy V-notch, fatigue, and stress corrosion cracking.

Effect of Austenitizing Temperature

An interesting effect discovered early in the research was that austenitizing temperatures several hundred degrees higher than those conventionally used resulted in increases in fracture toughness of 50 percent to 100 percent above those obtained with conventional heat treating procedures. This effect is shown in Fig. 10 for ATSI 4130 steel, in Fig. 11 for AIST 4330 steel, and in Fig. 12 for ATSI 4340 steel. The marked improvement in fracture toughness produced by quenching from $1200^{\circ} \mathrm{C}$ instead of $870^{\circ} \mathrm{C}$ is clearly evident. How ever, the tempered martensite embrittlement effect, which is clearly indicated for al1 three steels when they were quenched from $1200{ }^{\circ} \mathrm{C}$, was hardly noticeable for the same steels when they were oil quenched from $870^{\circ} \mathrm{C}$. Retained austenite was present at the lath boundaries. This was confirmed by selected area diffraction electron microscopy, which revealed substantial amounts of retained austenite in the form of lath boundary films in the specimens quenched from $1200{ }^{\circ} \mathrm{C}$, with a lesser amount in the 4340 steel oil quenched from $870{ }^{\circ} \mathrm{C}$, and sti11. less for the 0.30 percent carbon steels quenched from the lower temperature. Decomposition of the retained austenite accounts for the observed embrittlement. Optical microscopy did reveal a significant feature in the $870{ }^{\circ} \mathrm{C}$ oil quenched 4130 steel; both upper bainite and small islands of 
blocky ferrite were visible. These features were not evident in the same steel quenched from the higher temperature.

The improvement in fracture coughness produced by higher austenitizing temperatures could be attributed to a number of factors, including a beneficial effect provided by the presence of thin layers of undecomposed austenite between the martensite laths, but no positive conclusions could be reached about the effect of the austenite without additional investigations being performed.

The next series of experiments (69) was made with a simplex steel, one containing only 5.0 percent molybdenum as an alloy element. "Wo carbon contents, 0.30 and 0.41 were used. Other elements were 0.6 percent manganese, 0.005 percent sulfur, and 0.008 percent phosphorous. The alloys were vacuum melted and subsequently forged to size. Specimens of these alloys were austenitized at various temperatures ranging fron $870^{\circ} \mathrm{C}$ to $1250^{\circ} \mathrm{C}$ and were iced brine quenched. All specimens were martensttic throughout in the asmuenched con dition, although they had atotempered during quenching. The tensile strengths, yield strengths, and fracture toughnesses obtained are show as a function of quenching temperature in Fig. 13. There were large spherical undissolved carbide particles present in both the 0.30 and 0.41 percent carbon alloys after quenching fxom $870^{\circ} \mathrm{C}$. Tt is well known that such particles act as fracture nuclei even when the fracture is of the relatively ductile dimplerupture type, as was the case for the alloys being tested. Tiny cracks form locally at undissolved particles and chese microcracks join together by local shear tearing as plastic flow proceeds. This results in a low value of Eracture toughness. At highex austenitizing temperatures, the carbide particles dissolve completely and the fracture toughess is higher by a factor of 
approximately two. The effect of carbide solution is also evident in the tensile and yield strenghts, which show increasing values with increasing austenitizing temperature. The effect of austenite grain size per se was checked with two 0.35 percent carbon lower alloy steels, one containing one percent molybdenum, the other one pexcent molybdenum and three percent nickel. In both of these steels the ASTM austenite grain size was six at $870{ }^{\circ} \mathrm{C}$ and one at $1200{ }^{\circ} \mathrm{C}$. A11 of the carbon was in solution in these steels at the lower temperature, so there were no undissolved carbides present. For both steels, the fracture toughnesses were found to be independent of the prior austenite grain size. In this case, there was no improvement when higher austenitizing temperatures were employed (as was found for the 5 percent molybdenum alloy steels). However, the improvement obtained with higher austenitizing temperatures for the 4330 and 4340 steels could not be attributed to the effect of undissolved carbides, because the carbon was also in solution in these steels at $870^{\circ} \mathrm{C}$. Hence the toughness enhancement could seemingly be attributed to the presence of the retained austenite films. Austenite, in certain cases seems to be beneficial but, can also be detrimental, particularly when it contains high carbon, is unstable during plastic flow, and transforms to martensite. Also, austenite in blocky form does not appear to enhance toughness and tends to lower the yield strength.

Fracture Toughness vs. Charpy V-Notch Austenitizing AIST 4340 and similar steels at $1200{ }^{\circ} \mathrm{C}$ rather than $870{ }^{\circ} \mathrm{C}$ produces a remarkably beneficial effect on fxacture toughness. However, when Charpy Vwnotch tests are made on such steels, the higher austenitizing temperature was found to be detrimental $(70,71)$, with the energy being reduced from about 7 foot pounds for the $870{ }^{\circ} \mathrm{C}$ treatment to about 5.5 foot pounds for specimens austenitized at $1200{ }^{\circ} \mathrm{C}$, but cooled to $870{ }^{\circ} \mathrm{C}$ before oil 
quenching. Ritchie and coworkers ${ }^{(72)}$ studied this anomalous behavior and concluded that the effect was related to the difference in notch sharpness in the two different kinds of test specimens. The root radius of the charpy notch is $0.010 \mathrm{in} .(0.25 \mathrm{~mm})$, whereas the notch tip is that of a fatigue crack in fracture toughness specimens. Charpy bars are relatively small in cross-sectional area compared with fracture toughness specimens and plane strain conditions often do not exist during impact testing of Charpy specimens. Frequently shear lips occupy a substantial portion of the fracture surface area. In the case in question, however, the shear lips were very sma11, occupying only about four percent of the area of broken bars treated at either high or low austenitizing temperatures.

Scanning electron microscopy revealed that the fracture surfaces for both Charpy and $\mathrm{K}_{\mathrm{Ic}}$ test specimens were identical for a given heat treatment, but were different in nature for the two different austenitizing treatments. Specimens heated only to $870{ }^{\circ} \mathrm{C}$ exhibited quasi-cleavage and fibrous fractures, whereas those with the higher cemperature treatment fractured by intergranular and fibrous modes. Because the fracturemechanisms were identical in both Charpy and $\mathrm{K}_{\mathrm{Ic}}$ specimens for a given heat treatment, the reversal in order of toughness exhibited by the charpy specimens could not be attributed to a difference in fracture mechanism.

The factor found to be significant in controlling the behavior of the Charpy specimens was the radius at the root of the V-notch. Ritchie et al (72) determined the fracture toughnesses of Charpy specimens having different machined root radii, ranging from a fatigue crack to $0.023 \mathrm{in} .(0.58 \mathrm{~mm})$. The specimens were broken at $22{ }^{\circ} \mathrm{C}$ in an instrumented Charpy machine. 
Measurements were made of the energy absorbed and of the "apparent" dynamic fracture toughness, $\mathrm{K}_{\mathrm{A}}$, for specimens austenitized at $1200{ }^{\circ} \mathrm{C}$ and cooled to $870^{\circ} \mathrm{C}$ before oil quenching, and for a second series austenitized at $870{ }^{\circ} \mathrm{C}$ and quenched in oil directly from that temperature. The "apparent" fracture toughness refers to a value of $\mathrm{K}_{\mathrm{Ic}}$ measured ahead of a rounded notch. $\mathrm{K}_{\mathrm{A}}$ is generally used as a means of estimating the fracture toughness by means of Charpy specinens without recourse to fatigue precracking (73-75)。 Ritchie's data are shown in Fig. 14 for a 4340 steel in the two different austenitized conditions. In this figure, $\mathrm{K}_{\mathrm{A}}$ is plotted against the square root of the notch tip radius. An important feature of this plot is that for notch tip radil. less than $0.002 \mathrm{in.}(0.05 \mathrm{~mm})$, the toughness of the $1200-870^{\circ} \mathrm{C}$ austenitized specimens exceed that of the $870^{\circ} \mathrm{C}$ treated specimens, but for larger radii, the reverse is true. Thus, it was demonstrated that "notch toughness" is not only a function of the microstructure but is also stronly dependent upon the notch sharpness. A test specimen with a sharp notch may rate two steels with different microstructures in one order, whereas another test specimen with a blunt notch may rate the two in the reverse order. Neither $\mathrm{K}_{\mathrm{Ic}}$ nor the Charpy $V-n o t c h$ value alone is sufficient to provide an adequate appraisal of the "notch toughness" of a steel. 


\author{
EFFECTS ON MECHANICAL PROPERTIES OF RETAINED AUSTENITE, \\ ISOTHERMAL TRANSFORMATIONS, TEMPERING TEMPERATURE, AND SILICON
}

For the purpose of investigating the various factors that affect mechanical properties, and fracture toughness in particular, an aircraft-qualify, commercially-made AIST 4330 steel was selected as a base alloy ${ }^{(76)}$. This steel was remelted in a vacuum induction furnace and cast into 25-pound ingots that were homogenized 24 hours at $120{ }^{\circ} \mathrm{C}$ and then hot forged into bars suitable for heat treating and machining into fracture toughness specimens. For purposes of comparison, no compositional modifications were made to one me1t, but additions were made to three other melts. Silicon was added in amounts of one, two, and three percent. The effects of the silicon additions on the amounts of austenite retained at room temperature after various heat treatments (direct oil quenching from $900^{\circ} \mathrm{C}$, and when isothemally transformed at $200^{\circ} \mathrm{C}, 250^{\circ} \mathrm{C}$, and $350^{\circ} \mathrm{C}$ ) are shown in Fig. 15. The $\mathrm{M}_{\mathrm{S}}$ temperatures of a11 of the alloys were approximately the same, between 325 and $350{ }^{\circ} \mathrm{C}$. The amount of retained austenite varied widely with the heat treatment, being only 4 to 6 percent in aswquenched specimens, and ranging up to 20 percent for the 3 percent silicon material transformed isothermally at temperatures near the $\mathrm{M}_{\mathrm{S}}$. For the base 4330 steel, the amount of retained austenite was greater in specimens transformed isothemal1y at $200{ }^{\circ} \mathrm{C}$ and $250{ }^{\circ} \mathrm{C}$ than it was in the oil quenched specimens. The isothermal treatments provided time for carbon concentration in the untransformed austenite, thus stabilizing the austenite. At the higher isothermal transformation temperatures, the precipitation of cementite was suppressed by the silicon, partitioning of carbon into the austenite was enhanced, and high levels of retained austenite resulted. Control of the amount of austenite could be obtained by adjusting the silicon content 
of the alloy and transformation temperature. However, for the higher silicon steels, the carbon content of the retained austenite varied with heat treating procedure, ranging from 0.3 percent in as-quenched specimens to substantially higher concentrations in the material isothermally transformed at $350{ }^{\circ} \mathrm{C}$ (which contained 80 percent bainite and 20 percent austenite). The carbon content of the bainite was assumed to be about 0.25 percent (based upon work of Matas and Hehemann ${ }^{49}$, thexefore the untransformed austenite contained an average of about 0.5 percent of carbon. This difference in carbon content can effect major changes in mechanical behavior. Thomas and Das $(77,78)$ have shown that carbon contents above about 0.4 percent increase the amount of twinning in martensite which lowexs the fracture toughness. In the present case, however, the conditions differed substantially from those of Das and Thomas. The higher carbon austenite in the present work did not transform during cooling to room temperature. Furthermore, the retained austenite was highly dislocated by the plastic strains caused by the volume change associated with the bulk transformation.

The effects of silicon content and tempering temperature on the stability of the retained austenite when subjected to plastic deformation in a room cemperature tensile test are shown in Figs. 16 and 17. Although the base AIST 4330 had a higher level of recained austenite in the oil quenched condition than did the steel to which two percent silicon had been added ( 7 percent vs. 3 percent), the higher silicon steel was more stable during tempering. The austenite in both cases was highly unstable when plastically deformed. At Four percent tensile strain, most of the austenite had transformed. 
Comparisons showing differences in mechanical properties produced by dixect oil quenching to room temperature versus isothermal transformation at $250{ }^{\circ} \mathrm{C}$ are presented in Figs. 18 and 19. The elongation was higher for isothermally transformed tensile specimens than it was for those that were directly oil quenched, and did not vary significantly with tempering temperature for either case. The yield and ultimate tensile strengths were higher for oil quenched specimens than those of isothermally transformed, as would normally be expected, but the $K_{I c}$ values did not vary significantly between the two types of heat treatments. The optimum combination of properties was obtained with the 2 percent silicon steel, oil quenched and tempered at $300^{\circ} \mathrm{C}$. In this case, an unusually high $\mathrm{K}_{\mathrm{Ic}}$, $103 \mathrm{ksiV}$ in. (113 MPaVm), was measured, along with yield and tensile strengths of $220 \mathrm{ksi}(1500 \mathrm{MPa}$ ) and $260 \mathrm{ksi}$ (1800 MPa).

The beneficial effects of a 2 percent silicon addition to an AISI 4340 steel are shown in Fig. 20. The enhancements of both strength and toughness are evident in this figure. The 4340 steel is not quite as tough as 4330 , but it is substantially stronger. 


\section{EFEECT OF TRANSFORMATTON DURTNG CONTTNUOUS COOLING \\ ON MECHANICAL PROPERTTES}

For heavy sections of steel that are expected to harden all the way through during slow cooling, high pearlite hardenability is required for optimum combinations of strength and loughness. A commercial steel that meets these requiremonts is $300-M$, which contains the same $C$, Mn, Cr, and Ni as aircraftoquality 4340, but has 0.4 percent of Mo instead of 0.25 percent, 1.6 percent of Si instead of 0.23 percent, plus 0.1 percent of vanadium. In the present investigation, properties were determined for microstructures equivalent to those developed during air cooling of plates ranging from one to six inches In thickness. This was accomplished by controlled cooling of thinner pieces, with time-temperature curves selected to match those of air cooled thick plates. Both fracture toughness and Charpy V-notch tests were conducted in addition to conventional tensile tests. Slow cooling results in the retention of large quantities of austenite (up to 30 percent). The role played by the retained austenite was investigated. The morphologies, anounts, and mechanical stability of the austenite were determined. The stability of the austenite was found to vary with tempering treatment and the changes produced by tempering had major influences on fracture properties. When the austenite was stable under plastic strain conditions, the steel had good fracture properties; when the austenite was unstable, the fracture toughness was lower. Also, destabilization of the austenite during tempering results in tempered martensite embrittement. It was also found that there was an optimum slow cooling rate which resulted in the most desirable combinations of strength and toughness.

The continuous cooling transformation diagram is shown in Fig. 21 . The temperature differences between the plate centers and edges are small for air 
cooled plates, being less than $25^{\circ} \mathrm{C}$ for the thickest plates. The cooling rates in the cransformation temperature range, $400{ }^{\circ} \mathrm{C}$ to $200{ }^{\circ} \mathrm{C}$, were nearly identical throughout the plate thickness, thus uniformity of microstructure was assured.

A comparison of the amount of retained austenite in one-inch-thick oil quenched specimens and those cooled at a rate corresponding to a six-inch-thick aircooled plate is shown in Fig. 22 as a function of tempering temperature. The oil quenched specimens had about 5 percent in the as-quenched condition, which dropped to 4 percent for tempering temperatures of $300{ }^{\circ} \mathrm{C}$ to $400{ }^{\circ} \mathrm{C}$, and to nearly zero at $500^{\circ} \mathrm{C}$. The six-inch-thick "aix-cooled" specimens had 30 percent retained austenite before tempering, and retained 75 percent or more of the austenite up to a tempering temperature as high as $450^{\circ} \mathrm{C}$. The austenite in the oil quenched specimens, being lower in carbon than the austenite in the air-cooled material, was less stable and transformed almost completely in tensile test specimens strained only 2 percent at room temperature. Austenite in the air-cooled plate material, being higher in carbon, was more stable, with only a small fraction transforming during tensile straining. Tempering air-cooled material at $450^{\circ} \mathrm{C}$ caused some carbide to precipitate from the austenite, thus reducing its stability. As a consequence, more than half of the 22 percent was transformed by tensile straining of 2 percent. Fig. 23 shows the Charpy $V$-notch energy and $\mathrm{K}_{\mathrm{IC}}$ values versus tempering temperature for both oil-quenched and air-cooled, 6-inch-thick plate specimens. Unlike the results discussed earlier for AISI 4340 steel austenitized at $870{ }^{\circ} \mathrm{C}$ and at $1200{ }^{\circ} \mathrm{C}$, where the Charpy values were lowered and the $\mathrm{K}_{\mathrm{Ic}}$ values were raised by the higher austenitizing temperature, the direction of the effect of heat treatment was the same for $K_{I c}$ and Charpy $V$-notch in the case for oil 
quench and slowly-cooled 300-M. Thus, both Charpy and $\mathrm{K}_{\mathrm{Ic}}$ were excellent indicators of the effect of microstructure on the notch toughness. As would be anticipated, the presence of large amounts of retained austenite lowers the tensile yield and ultimate strengths, as shown in Fig. 24, whereas it increases the tensile ductility, as shown in Fig. 25.

The effect of retained austenite on mechanical properties has been studied by many investigators. Webster ${ }^{(79)}$ showed that retained austenite seemed to improve fracture toughness of martensitic stainless steels. Jin et al (80) and Pampillo and Paxton ${ }^{(81)}$ found that the retained austenite played an ambiguous role in maraging steels. It has been established, however, that austenite can be conditioned to impart unusually high values of tensile ductility and Eracture toughness in TRIP steels by transforming during plastic deformation $(82-84)$. Also, others $(70,76,85)$ have found that retained austenite is sometimes associated with enhanced fracture toughness in ultra-high-strength steels. The influence of austenite is certainly not always favorable, and in certain instances it may be very bad, as is clearly indicated by the present research. The precipitous drop in both Charpy energy nad $K_{\text {Ic }}$ that occurs at a tempering temperature of $450^{\circ} \mathrm{C}$ in $\mathrm{rig} .23$ is due to the retained austenite which is destabilized and partially decomposes, forming carbide films at lath boundaries. At lower rempering temperatures, the carbon remains in solution in the austenite, embritting carbide films do not form, and both charpy and $K_{\text {Ic }}$ values are enhanced by the relatively stable austenite (Fig. 23), and so is the tensile ductility (Fig. 25); It seems likely that these beneficial effects are at least in part due to the three percent volume increase associated with the FCC to BCC phase change which occurs during plastic straining. This volumetric expansion relaxes the high local tensile stresses around fracture nucleating centers and dolays the onset of microcrack formation. The effect 
of plastic strain on austenite stability in air-cooled specimens, indicated in Fig. 22 for 2 percent strain, continues in a tensile test at higher strains; half of the austenite is transformed at 10 percent strain and on]y a few percent remains at 20 percent strain. This type of straininduced transformation was found necessary for enhanced ductility and toughness in TRIP steels, and the same behavioral relations seem to prevail in the air-cooled, 300-M steel. 
MICROSTRUCTURAL INELUENCES ON CRACK GROWTH RATES IN FATTGUE TESTS

The use of fracture mechanics concepts for evaluating crack growth rates during cyclic loading has gained widespread attention since it was first introduced in 1963 by Paris and Exdogan ${ }^{(86)}$. In recent years, a great deal of data have been published relating crack propagation rates to yield strength, mean stress, microstructure, stress state, and environment ${ }^{(87-95)}$. Concurrent with the fracture mechanics research approach to fatigue, studies of fracture mechanisms and microstructural influence have been underway, so that it is now possible to relate microstructural features to variations in macroscopic crack growth behavior. Some results of recent work will be discussed to indicate the status of research in this field of study.

Most investigations have confirmed that the fatigue crack growth rate, da/dN is controlled by the cyclic stress intensity range, $\Delta \mathrm{K}$. The relationship is represented by $(86)$

$$
\mathrm{da} / \mathrm{dN}=\mathrm{C} \Delta \mathrm{K}^{\mathrm{m}}
$$

where $\mathrm{da} / \mathrm{dN}$ is the increase in crack length per cycle, $\mathrm{C}$ and $\mathrm{m}$ axe experimental constants, and $\Delta \mathrm{K}$ is the difference between the maximum and minimum stress intensties during cyclic loading. This equation accurately defines the crack growth behavior in the midrange of da/dN, which is approximately $10^{-5}$ to $10^{-3} \mathrm{~mm} /$ cycle, but it does not apply at high growth rates where $\mathrm{K}_{\max }$ approaches $K_{I c}$, nor does it apply at low growth rates where $\Delta \mathrm{K}$ approaches the stress intensity range, $\Delta \mathrm{K}_{0}$, below which a crack wil1 not grow $(95,96,97,100,101)$. The three stages of crack growth rates are shown schematically in Fig. 26. Different mechanisms of fracture have been observed in the $A, B$, and $C$ regimes illustrated in the figure. In regime B, fracture occurs by a transgranular 
ductile mechanism. In this region, there is little influence of microstructure or of the mean stress, $\mathrm{R},\left(\mathrm{K}_{\min } / \mathrm{K}_{\max }\right)$ on the crack growth rate ${ }^{(96-98)}$. In regime $\mathrm{C}$, where $\mathrm{K}_{\max }$ approaches $\mathrm{K}_{\mathrm{Ic}}$, the growth rate is rapid and is highly sensitive to differences in both microstructural features and the mean stress. In this range the growth rate increases rapidly with increases in $\Delta \mathrm{K}$, and failures occur by modes that are characteristic of static fractures, including cleavage, intergranular, and fibrous fracture ${ }^{(96-98)}$. In regime $A$, where cracks increase in length very slowly, the influences of microstructure ${ }^{(99-103)}$ and mean stress $(99-111)$ on growth rates can be large. The behavior in the region of low $\Delta K$ is also sensitive to the stress history (118) and to the environmental conditions. Even an air environment has a deleterious effect, as has been demonstrated by tests on the same materials in vacuum and in air $(100,101,109,113,114)$. Lower propagation rates and higher threshold values $\left(\Delta \mathrm{K}_{0}\right)$ were obtained in vacuum tests when compared with test results in air. Also, the effects of mean stress found in tests conducted in air were not observed when tests were made in vacuum $(107-120)$.

A comprehensive report on this subject has recently been prepared by Ritchie ${ }^{(115)}$. An example of the type of results obtained by Ritchie (116) is presented in. Fig. 27. This figure shows crack growth rate curves for 300-M steel in three conditions of heat treatment, oil quenched from $870^{\circ} \mathrm{C}$ and tempered at two different temperatures, $300^{\circ} \mathrm{C}$ and $470^{\circ} \mathrm{C}$, and as isothermally transformed at $250^{\circ} \mathrm{C}$ (about $50^{\circ} \mathrm{C}$ below the $\mathrm{M}_{\mathrm{S}}$ ) followed by tempering at $300^{\circ} \mathrm{C}$. The isothermally transformed steel and the quenched steel tempered at $470{ }^{\circ} \mathrm{C}$ had identical 0.2 percent yield strengths. Their microstructures differed significantly, however, with the isothermally treated specimens retaining about ten percent of untransformed austenite and the quenched $470{ }^{\circ} \mathrm{C}$ tempered specimens containing little or no austenite. 
Several important features are evident in the results shown in Fig. 27. These include the effect of the yield strength on the threshold stress intensity, $\Delta K_{0}$, the effect of retained austenite in steels having the same static yield strength, and the importance of the stress ratio $R$, which is defined as $\mathrm{K}_{\min } / \mathrm{K}_{\max }$. As has been demonstrated by Ritchie ${ }^{(115)}, \Delta \mathrm{K}_{\circ}$ is inversely related to the yield strength. This relationship is illustrated in the figure which shows that at $\mathrm{R}=0.05, \Delta \mathrm{K}_{0}=2.7 \mathrm{ksi} / \mathrm{in} .(3 \mathrm{MPa} / \mathrm{m})$ Eor the quenched specimens tempered at $300^{\circ} \mathrm{C}$ (YS $=253 \mathrm{ksi}$ or $\left.1737 \mathrm{MPa}\right)$ and $\Delta \mathrm{K}_{0}=4.5 \mathrm{ksi} / \mathrm{in} .(5 \mathrm{MPa} / \mathrm{m})$ for the quenched specimens tempered at $470{ }^{\circ} \mathrm{C}(Y \mathrm{~S}=218 \mathrm{ksi}$ or $1497 \mathrm{MPa})$. Judging from this relationship, the isothermally treated specimens should have a $\Delta \mathrm{K}_{0}$ value equal to the quenched specimen tempered at $470^{\circ} \mathrm{C}$, because of their identical yield strengths. However, this was not found to be the case; the 1sothermally treated material had a $\Delta K_{0}=3.2 \mathrm{ksi} / \mathrm{in} .(3.5 \mathrm{MPa} / \mathrm{m})$ which was substantially lower than expected. As a consequence of this and similar observations, Ritchie (121) concluded that the basis for correlation should be the yield strength under cyclic loading rather than the static value. The cyclic loading yield strength is generally significantly different from the static value, and may be elther higher or lower, depending upon the microstructure of the alloy. For the case in question, the static yield strength was $218 \mathrm{ksi}$ (1497 MPa) for both the quenched specimens tempered at $470{ }^{\circ} \mathrm{C}$ and the isothermally treated material, but the yield strengths under cyclic loading were $174 \mathrm{ksi}$ (1198 MPa) and $219 \mathrm{ksi}(1502 \mathrm{MPa})$, respectively. The cyclic loading yield strengths were found to correlate well with $\Delta \mathrm{K}_{0}$ values for a number of strength levels of 300-M steel. The flow stresses within the cyclic plastic zone ahead of the tip of the crack are governed by the cyclic rather than by the monotonic flow characteristics. The decrease in flow stress for from 
218 to $174 \mathrm{ksi}$ (1497 to $1198 \mathrm{MPa}$ ) for the quenched and tempered steel was thus considered to be responsible for the high value of $\Delta \mathrm{K}_{0}(4.5 \mathrm{ksi} / \mathrm{in}$ or $5 \mathrm{MPa} / \mathrm{m})$. The decrease in flow stress observed in cyclically loaded quenched and tempered steel is generally attributed to a rearrangement of the dislocation substructure and a reduction in dislocation density over that produced by monotonic loading. The absence of a decrease in yield strength of the isothermally transformed steel when cyclically loaded resulted from the strengthening effect of strain induced austenite transformation which offset the weakening effect in the tempered bainite and martensite produced by the cyclic loading. At the higher value of $\mathrm{R}=0.70$, the threshold $\Delta \mathrm{K}_{\mathrm{o}}$ values were al1 considerably lower than for the $R=0.05$ tests, being about $2.1 \mathrm{ksi}$ $\sqrt{ }$ in. $(2.3 \mathrm{MPa} / \mathrm{m})$ for the steel in all three conditions of heat treatment. The evidence strongly indicates that metastable retained austenite is deleterious under cyclic loading at low values of $\Delta K$ when $R$ is small.

In the $C$ regime, however, the presence of metastable retained austenite is beneficial. When $\mathrm{K}_{\max }$ approaches $\mathrm{K}_{\mathrm{Ic}}$, the behavior under cyclic loading is governed primarily by the fracture toughness. The resistance to crack growth provided by the transformation of retained austenite in a fracture toughness test also contributes to a retardation of crack growth during cyclic loading and fracture does not occur until higher values of $\triangle \mathrm{K}$ are reached. Thus, even in a given test, retained austenite can be beneficial or detrimental, depending upon the stress state, as shown by the curve in Fig. 27 for the isothermally transformed steel at $\mathrm{R}=0.05$. In the regime of low $\Delta \mathrm{K}$, retained austenite lowers $\Delta \mathrm{K}_{0}$, but in the regime of large $\Delta \mathrm{K}$, retained austenite delays ultimate faflure. 


\section{MICROSTRUCTURAL INFLUENCES ON CRACK GROWTH RATES \\ UNDER STATTC LOADING CONDITIONS}

The effect of retained austenite on the stress corrosion cracking of steels with high yield strengths has received relatively little attention. Webster (123) found that a direct correlation existed between the amount of retained austenite and the threshold stress intensity, $\mathrm{K}_{I S C C}$, below which cracking does not occur, in high strength martensitic stainless steel. It is generally known that austenitic steels are not particularly sensitive to hydrogen embrittlement, whereas high strength quenched and tempered steel are particularly sensitive to such embrittlement. A generally accepted embrittling mechanism for stress corrosion cracking of high strength steels involves hydrogen produced by cathodic reaction in an aqueous environment which enters the metal lattice, diffuses to the region of high triaxial tension stresses that exist ahead of the crack tip, lowers the cohesion in this region, and thereby promote microcracking. The stress axption $(117,118)$ or decohesion $(119,120)$ theories are presumed to be applicable in the present case ${ }^{(121)}$. Compact tension cests specimens of the type used to determine fracture toughness ${ }^{(78)}$ were used for the crack growth rate stuides. The applied load was constant throughout a single test. The specimens were immersed in a 3.5 percent sodium chloride solution during testing. However, the results with the salt solution did not differ from those of similar tests obtained with distilled water.

The $300-\mathrm{M}$ steel used in this investigation was the same steel used for the cyclic stress crack growth investigations discussed in the preceding section. Also, the heat treatments producing identical monotonic loading yield stress values were used for the stress corrosion crack growth rate measurements, namely oil quenched from $870{ }^{\circ} \mathrm{C}$ and tempered at $470{ }^{\circ} \mathrm{C}$, and 
isothermally transformed at $250{ }^{\circ} \mathrm{C}$ followed by cempering at $300^{\circ} \mathrm{C}$. Curves showing the crack growth rate versus stress intensity are plotted in Fig. 28 for 300-M steel in each of the two heat treated conditions. In both conditions, the threshold stress intensity was approximately $16.4 \mathrm{ksi} / \mathrm{in}$. $(18 \mathrm{MPa} / \mathrm{m})$. This result is consistent with the concept that plastic flow at the notch tip is necessary for crack growth in order to expose a fresh reactive surface, and both heat treatments produced identical flow characteristics at stresses near the yield strength. At higher stress intensities, the crack growth rate of the steel in the isothermally treated state was lower than that for the quenched and tempered condition by a factor of about six, and the total times to fracture differed by a factor of two. The lower crack growth rate and the higher fracture toughness (requiring a longer crack) both contributed to the extended lifetime of the isothermally treated material. The higher fracture toughness is associated with the strain induced transformation of the retained austenite present in the longer life steel. The crack growth rates in the plateau regions shown in Fig. 28 are independent of the stress intensity because the rate limiting process is the time required for hydrogen to diffuse from the crack tip to the region in the specimen where the triaxial stress is a maximum, where it must increase to the critical concentration requixed for local decohesion before the crack can move forward in a stepwise manner. The plateau velocity is presumed to be related to the bulk diffusion rate of hydrogen, and the diffusivity of hydrogen through austenite is several orders of magnitude lower than through ferrite ${ }^{\text {(122) }}$. Therefore, it seems logical to conclude that the presence of interlath austenite is a beneficial microstructural feature in a stress corrosion cracking environment because it acts as barriers which retard the rate of migration of hydrogen through the steel. 
SUMMARY

I have attempted to show how some fine-scale microstructural features that can be produced and controlled in heat treatable, high-strength steels affect fracture characteristics for a variety of loading and environmental conditions. Retained austenite in the form of interlath films, for example, can be heneficial or detrimenta1, depending upon the environment and imposed stress state. The amount of retained austenite can be varied from zero to thirty percent in a single alloy steel, such as $300-M$, by varying the heat treating procedure. The stability of the austenite can also be controlled, so that it can be made to transform slowly during plastic straining - a process that enhances fracture toughness.

There is still a great deal to learn about the reactions that can occur and the microstructures that they produce in multicomponent heat treatable steels, but all of the important reactions and the fine-scale microstructural. features can be determined with modern techniques and equipment. It should soon be possible to design new steels to meet the specific requirements For advanced technological applications. We plan to continue our efforts toward the attainment of this goal. 
ACRNOWLEDGEMENTS

The original research reported herein has been a group effort extending over a period of several years. Professor Victor Zackay and I have participated equally in guiding the research. We were fortunate to have Dr. Robert 0 . Ritchie working with us during the past two years while he was at the University of California, Berkeley, on a Miller Research Post Doctoral Fellowship. Much of the research was conducted by our group of excellent graduate students, including Ana-Maria Llopis, Dilip Bahandarkar, M. Shanthidas Bhat, Ronald Horn, Gabriel Kohn, Maric Castro-Cedeno, Paul Zajchowski, Thomas Tom, George Lai, and william Wood. Our appreciation is also expressed to Professor Gareth Thomas, whose advice and assistance with the transmission electron microscope studies was invaluable.

The research was supported by the Division of Physical Research of the U.S. Energy Research and Development Administration, and was conducted in the Materials and Molecular Research Division of the Lawrence Berkeley Laboratory, University of California, Berkeley. 
FIGURE CAPTIONS

Figure 1. Transmission electron micrograph of autotempered martensite showing presence of epsilon carbide. Many dislocations and some $\mathrm{Fe}_{3} \mathrm{C}$ are also present.

Figure 2. Curves showing percent of carbon precipitated from martensite vs. time at various temperatures for AISI 1046, AISI 4340, 300-M, and AIST $4340+3$ Si steels.

Figure 3. Effect of carbon on temperature change from upper to lower bainite for some $0.5 \% \mathrm{MotB}$ and $0.5 \% \mathrm{MO}_{3} 1 \% \mathrm{Cr}+\mathrm{B}$ steels (after Pickering ${ }^{(43)}$ ).

Figure 4. Effect of carbon on temperature change from upper to lower bainite, comparing Pickering"s results with those from present experiments. The region of transition from lower to upper bainite depends on the eutectoid composition, which shifts to lower carbon contents with higher concentrations of alloying elements such as those used in high hardenability steels.

Figure 5. TTT diagram for a steel containing $0.17 \% \mathrm{C}$ and $1.0 \% \mathrm{Cr}$.

Figure 6. TTT diagram determined by magnetic saturation method which permitted detection of the lower bainite reaction below the $\mathrm{M}_{\mathrm{S}}$ temperature.

Figure 7. Bainite start and ending curves for three steels, all containing $0.29 \%$ C. One steel contained one percent of nickel, the second 
contained one percent of chromium, and the third steel contained one percent each of nickel and chromium. The effects of nicke1 and chromium are not additive.

Figure 8. Reciprocal of reaction temperature vs. negative 1 og of time for vaxious "equivalent states" of the austenite decomposition reactions for a steel containing $0.29 \% \mathrm{C}$ and $1.0 \% \mathrm{Ni}$, illustrating that activation energy determinations are impossible to obtain from such data.

Figure 9. Transmission electron micrographs showing morphologies of carbides in upper and lower bainites. In upper bainite $\mathrm{Fe}_{3} \mathrm{C}$ is present in the form of stringers between upper bainite ferrite laths. In lower bainite epsilon carbide precipitates uniformly as small particles with the crystallographic relationship being $(0001) \varepsilon \|(011) \alpha$ and $[10 \overline{1} 1] \varepsilon \|[101] \alpha$. (See Figure 1.)

Figure 10. Plots of room temperature plane strain fracture toughness versus tempering temperature for AISI 4130 steel austenitized at various temperatures and quenched in oil or iced brine. The iced brine quenched specimens were cooled to liquid nitrogen temperature prior to quenching.

Figure 11. Plots of room temperature plane strain fracture toughness versus tempering temperature for AISI 4330 steel, austenitized at $1200{ }^{\circ} \mathrm{C}$, iced brine quenched and cooled to liquid nitrogen prior to tempering, compared with specimens austenitized at $870^{\circ} \mathrm{C}$ and oil quenched. 
Figure 12. Plots of room temperature plane strain fracture toughness versus tempering temperature for AISI 4340 steel, austenitized at $1200^{\circ} \mathrm{C}$ then cooled to $870^{\circ} \mathrm{C}$ before oil quenching, compared with specimens austenitized at $870{ }^{\circ} \mathrm{C}$ and oil quenched.

Figure 13. Plots showing influence of austenitizing temperature on room temperature fracture toughness $\left(\mathrm{K}_{\mathrm{Ic}}\right.$ or $\left.\mathrm{K}_{\mathrm{Q}}\right)$, yield strength, and ultimate strength of $0.3 \% \mathrm{C}, 5.0 \% \mathrm{Mo}$ stee1, and $0.41 \% \mathrm{C}, 5.0 \% \mathrm{Mo}$ stee1. Tests were conducted on specimens quenched in iced brine and not cempered.

Figure 14. The relationship between toughness, measured by the apparent dynamic fracture toughness $\left(K_{A}\right)$ from instrumented charpy tests, and notch root radius $(\rho)$ for oil quenched AISI 4340 steel in two conditions, austenitized at $1200{ }^{\circ} \mathrm{C}$, cooled to $870{ }^{\circ} \mathrm{C}$, oil quenched, and austenitized at $870^{\circ} \mathrm{C}$, oil quenched. $\rho_{0}$ is the limiting root radius and $\mathrm{K}_{\mathrm{Id}}$ is the dynamic fracture toughness. (Courtesy of R. O. Ritchie.)

Figure 15. Plots showing the influence of additions of silicon to a steel with a base composition similar to that of an AISI 4330 steel on the amount of austenite retained at room cemperature after a direct oil quench from the austenitizing temperature, and after isothermal transformation treatments at $200{ }^{\circ} \mathrm{C}, 250{ }^{\circ} \mathrm{C}$, and $350{ }^{\circ} \mathrm{C}$.

Figure 16. Variations in the volume fraction of retained austenite as a function of plastic strain in a room temperature tensile test after tempering at various temperatures, for oil quenched AISI 4330 steel. 
Figure 17. Variations in the volume fraction of retained austenite as a function of plastic strain in a room temperature tensile test after tempering at various temperatures, for an oil quenched AISI 4330 type steel to which $2 \%$ silicon had been added.

Figure 18. Plots showing the effects of tempering temperature on the mechanical properties of oil quenched AISI 4330 steel and AISI type 4330 steel to which $2 \%$ silicon had been added.

Figure 19. Plots showing the effects of tempering temperature on the mechanical properties of isothermally transformed AISI 4330 steel and AISI type 4330 steel to which $2 \%$ silicon had been added.

Figure 20. Plots showing the effects of tempering on the mechanical properties of AISI 4340 steel and AISI type 4340 steel to which $2 \%$ silicon had been added. Steels quenched from $870^{\circ} \mathrm{C}$ and $950{ }^{\circ} \mathrm{C}$, respectively.

Figure 21. Continuous cooling transformation diagram for 300-M steel. Curve 1 represents the time-temperature path for the center of a piece of moderace thickness during an oil quench. Curves 2 through 6 represent mid-thickness cooling curves for air-cooled plates ranging from one to six inches in thickness.

Figure.22. Retatned austenite in 300-M steel in oil quenched and tempered condition, and in aix-cooled and tempered six-inch-thick plate. Effect of straining $2 \%$ in a room temperature tensile test after cempering is also shown. 
Figure 23. Charpy $V$-notch energy versus tempering temperature for 300-M oil quenched and for air-cooled six-inch-thick plate shown in top figure, and fracture toughness, $K_{\text {Ic }}$, values shown below.

Figure 24. Tensile yield and ultimate strengths versus tempering temperature for oil quenched 300-M, and for air-cooled six-inch thick plates for same steel.

Figure 25. Tensile elongation and reduction in area versus tempering temperature for oil quenched 300 M steel, and for aix-cooled, six-inch-thick plate of same steel.

Figure 26. Schematic diagram showing relationships between the crack growth rate $(\mathrm{da} / \mathrm{dN})$ and the alternating stress intensity $(\Delta \mathrm{K})$.

Figure 27. Variations of fatigue crack growth rate with cyclic stress intensity are shown for 300-M steel in three conditions of heat treatment, oil quenched and tempered at $300{ }^{\circ} \mathrm{C}$, oil quenched and tempered at $470{ }^{\circ} \mathrm{C}$, and isothermally transformed at $250^{\circ} \mathrm{C}$, followed by tempering at $300{ }^{\circ} \mathrm{C}$. The isothermal treatment produced the same yield strength as did quenching plus $470^{\circ} \mathrm{C}$ tempering.

Figure 28. Crack propagation rate under static loading conditions for 300-M steel in two conditions of heat treatment. The fracture toughness type specimens employed were immersed in 3.5 percent salt solution (121). 




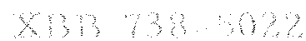

Higure 1. 


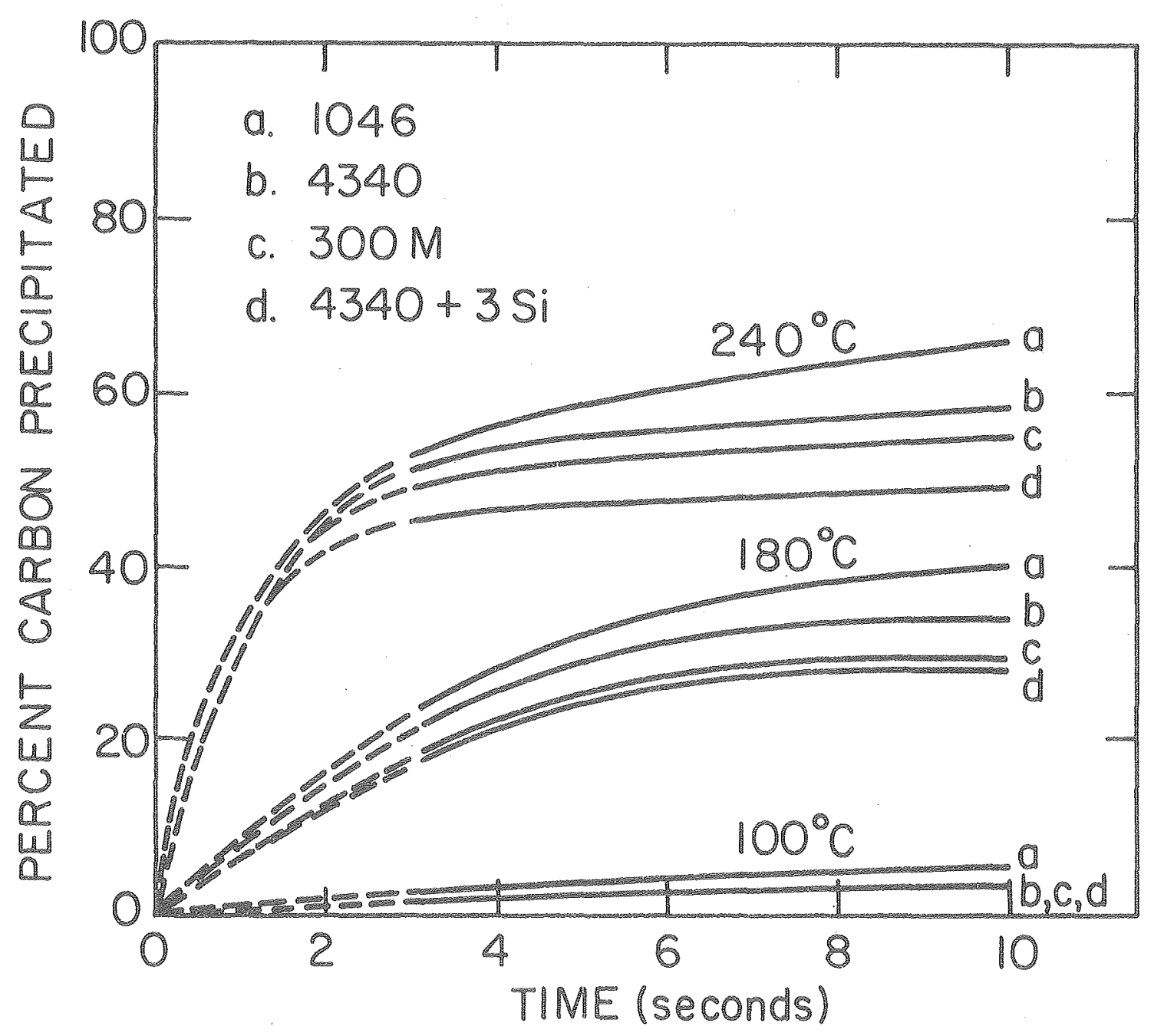

XBL772-5111

Figure 2。 


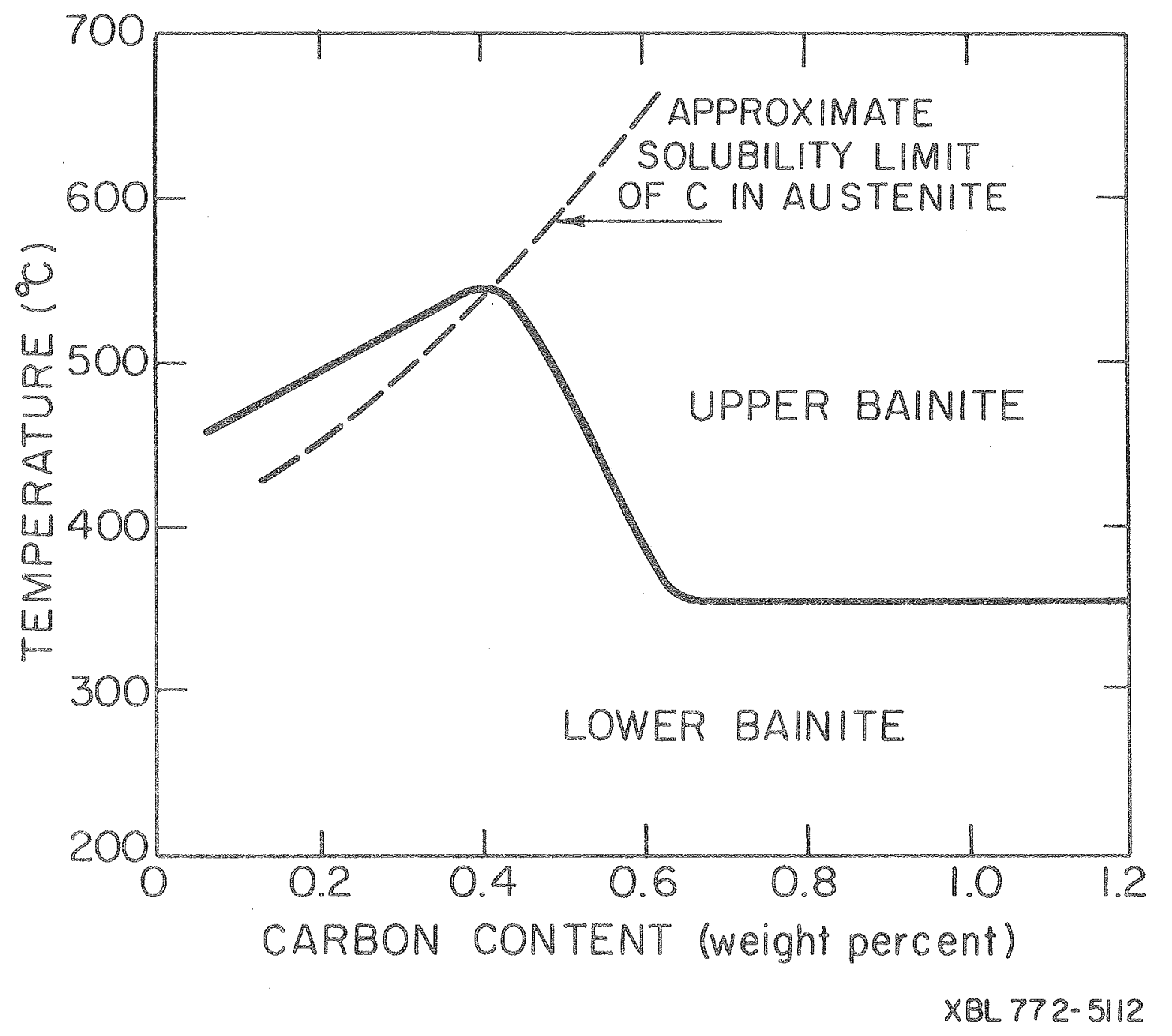

Figure 3. 


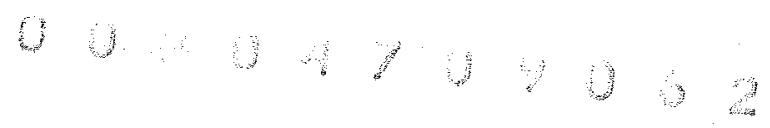

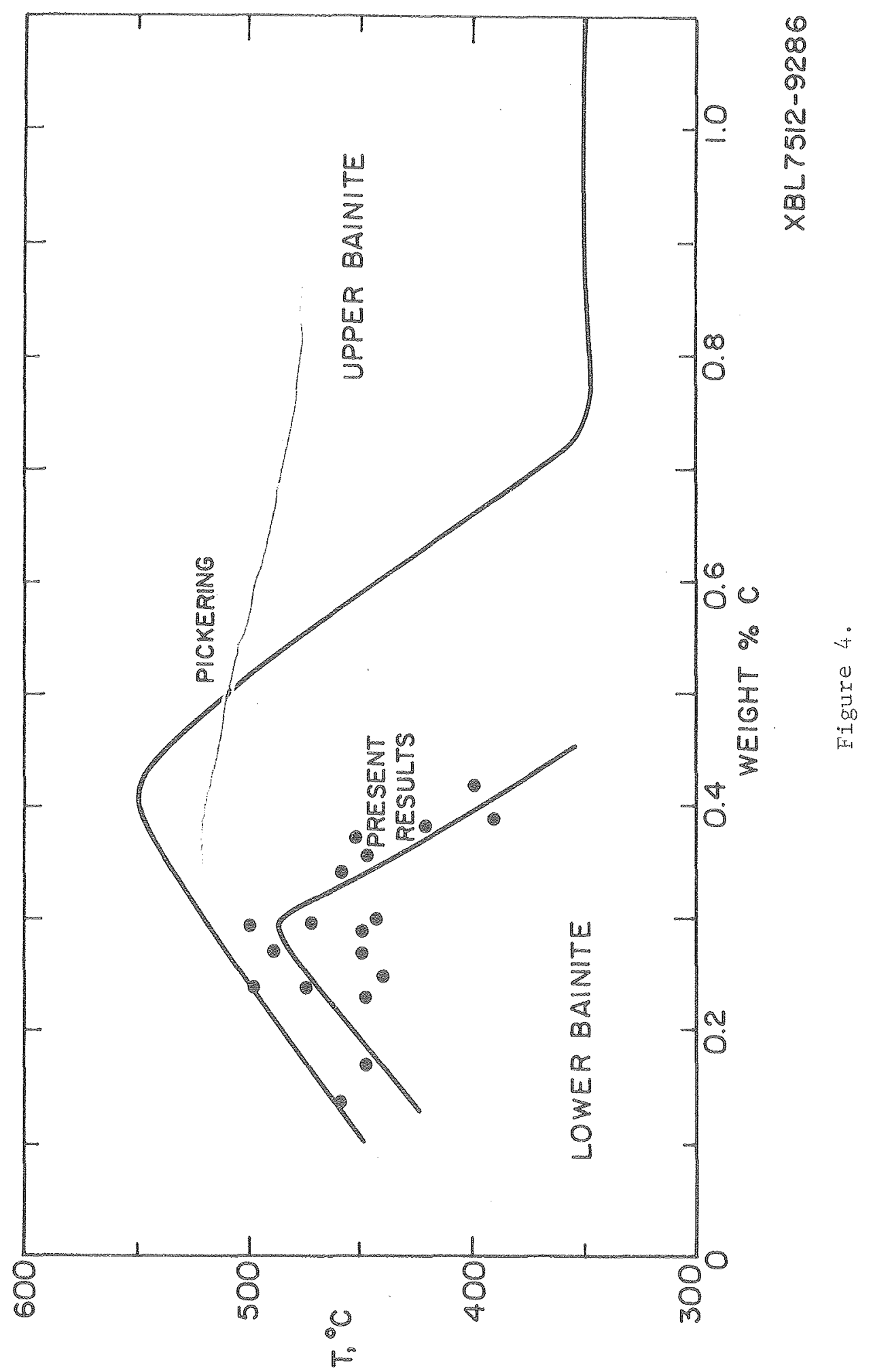




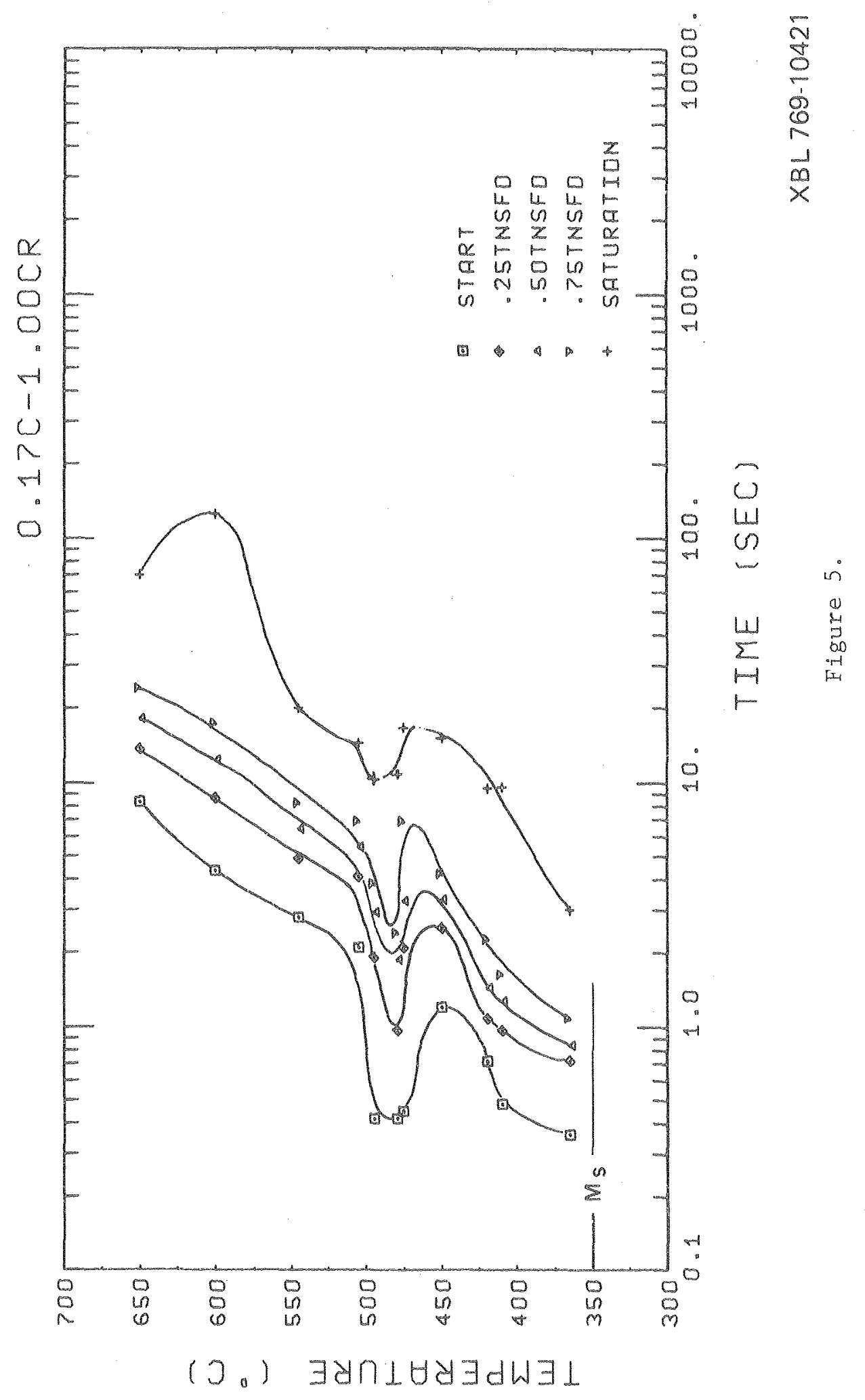




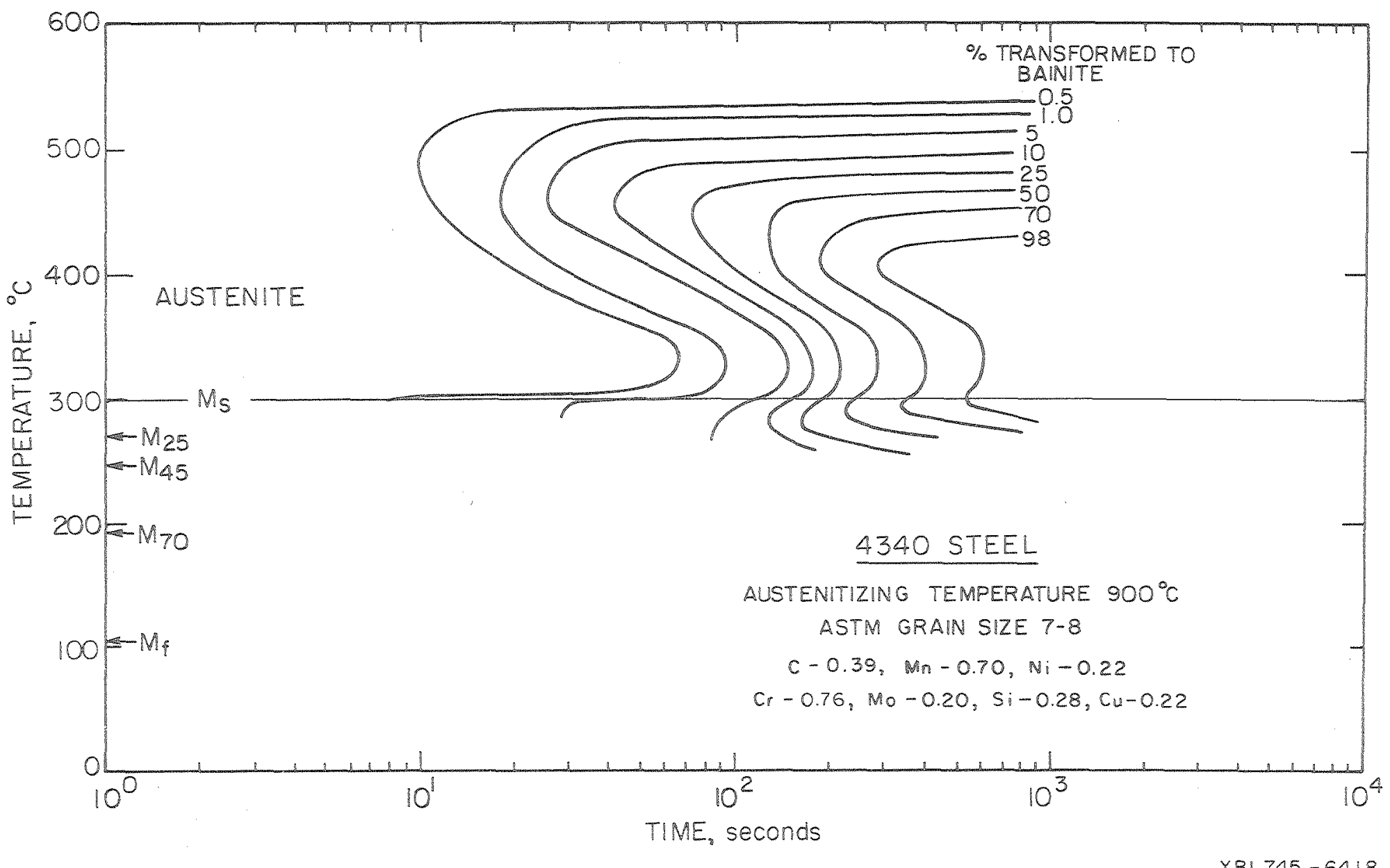

Figure 6. 


$40 \times 3.702064$

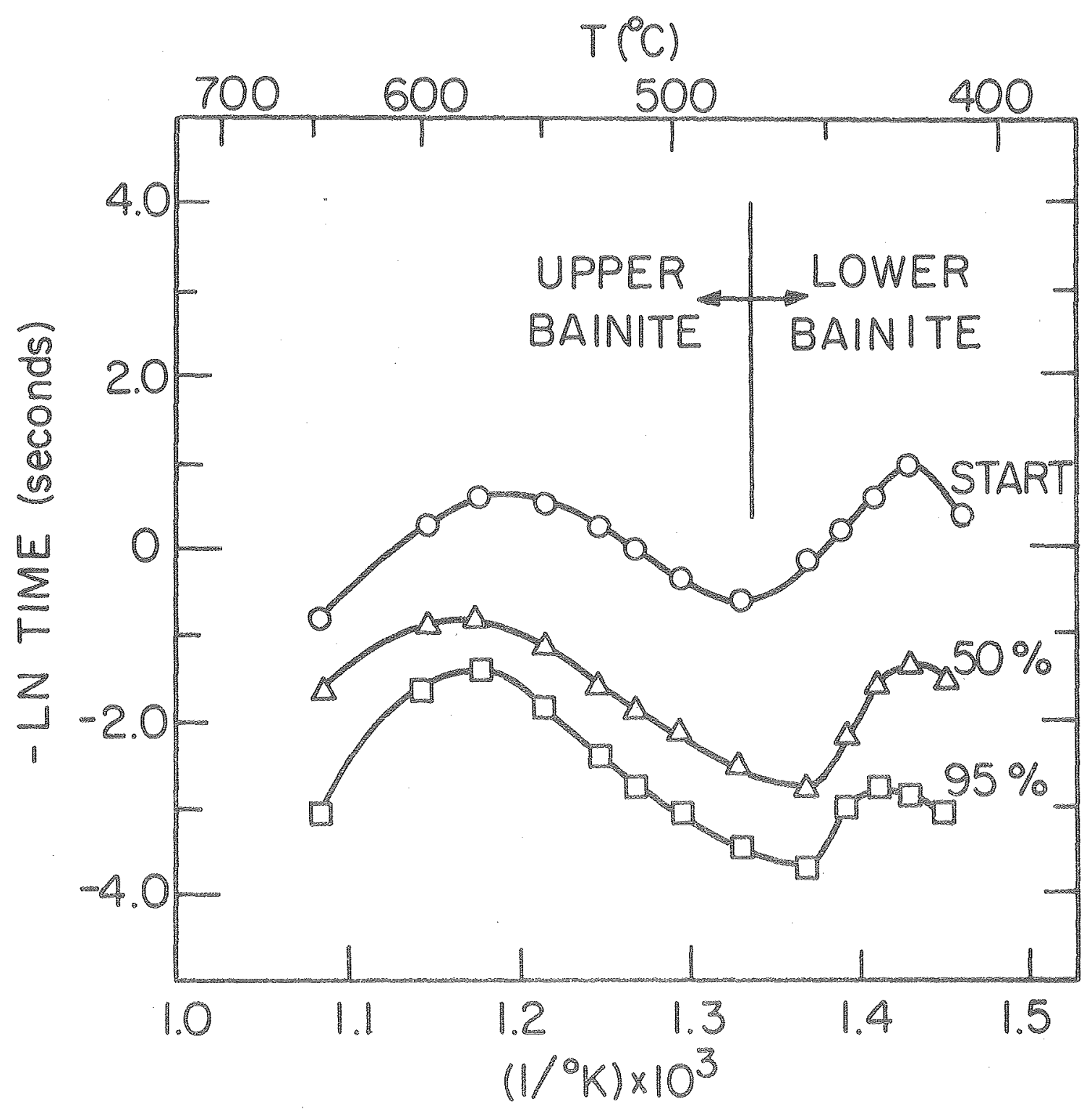

XBL772-5114

Figure 8. 

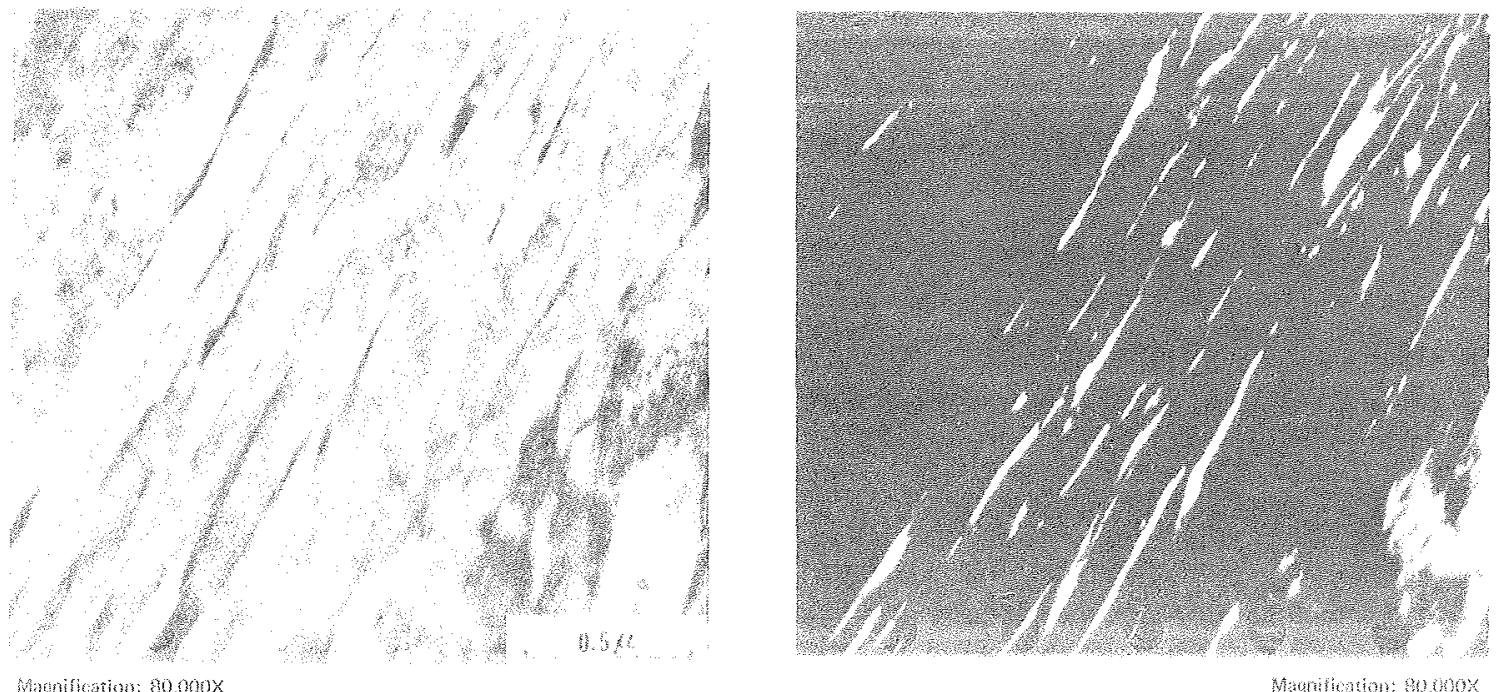

$\times 138729,1503$

Figure 9. 


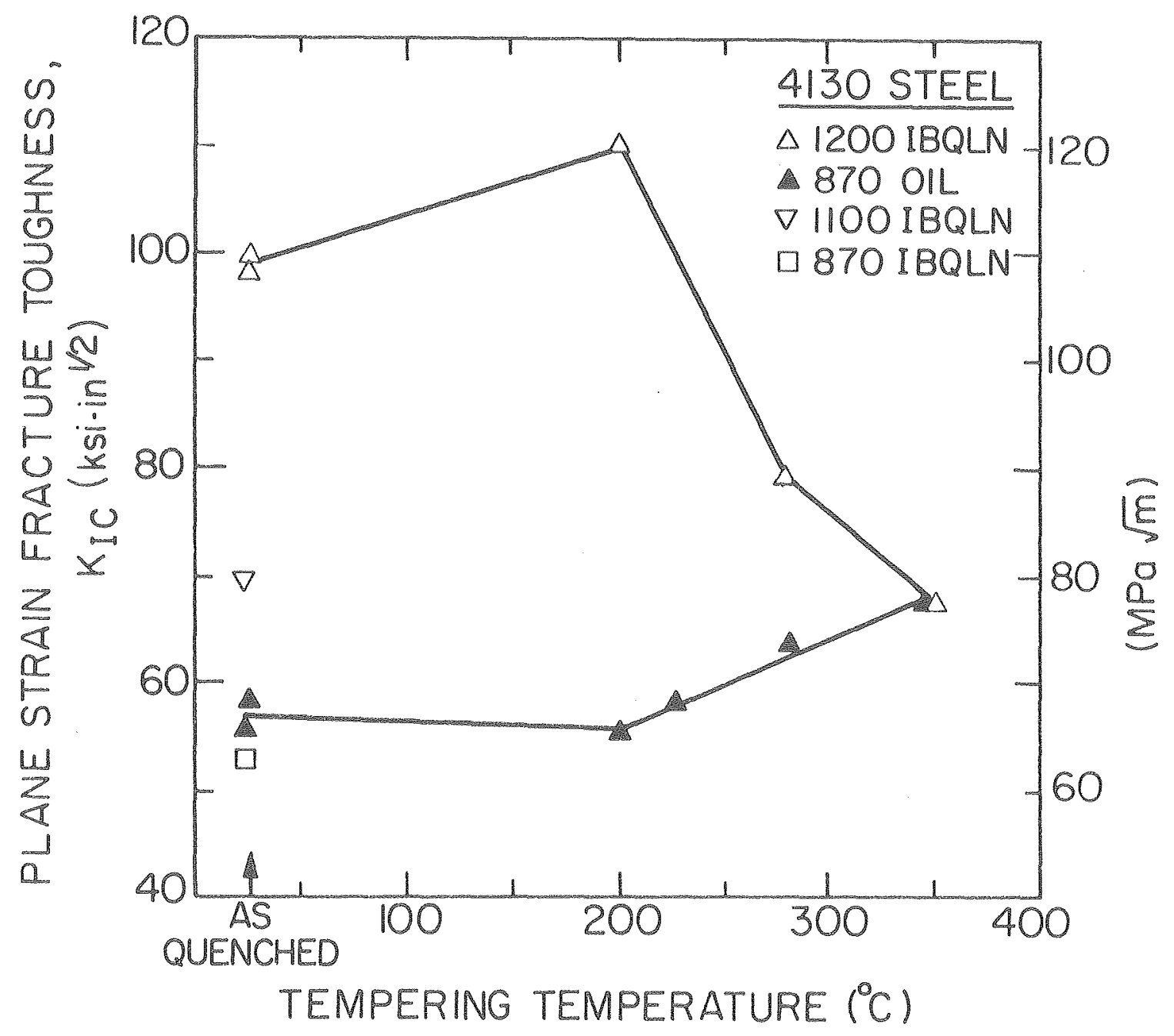

XBL772.5110

Figure 10. 


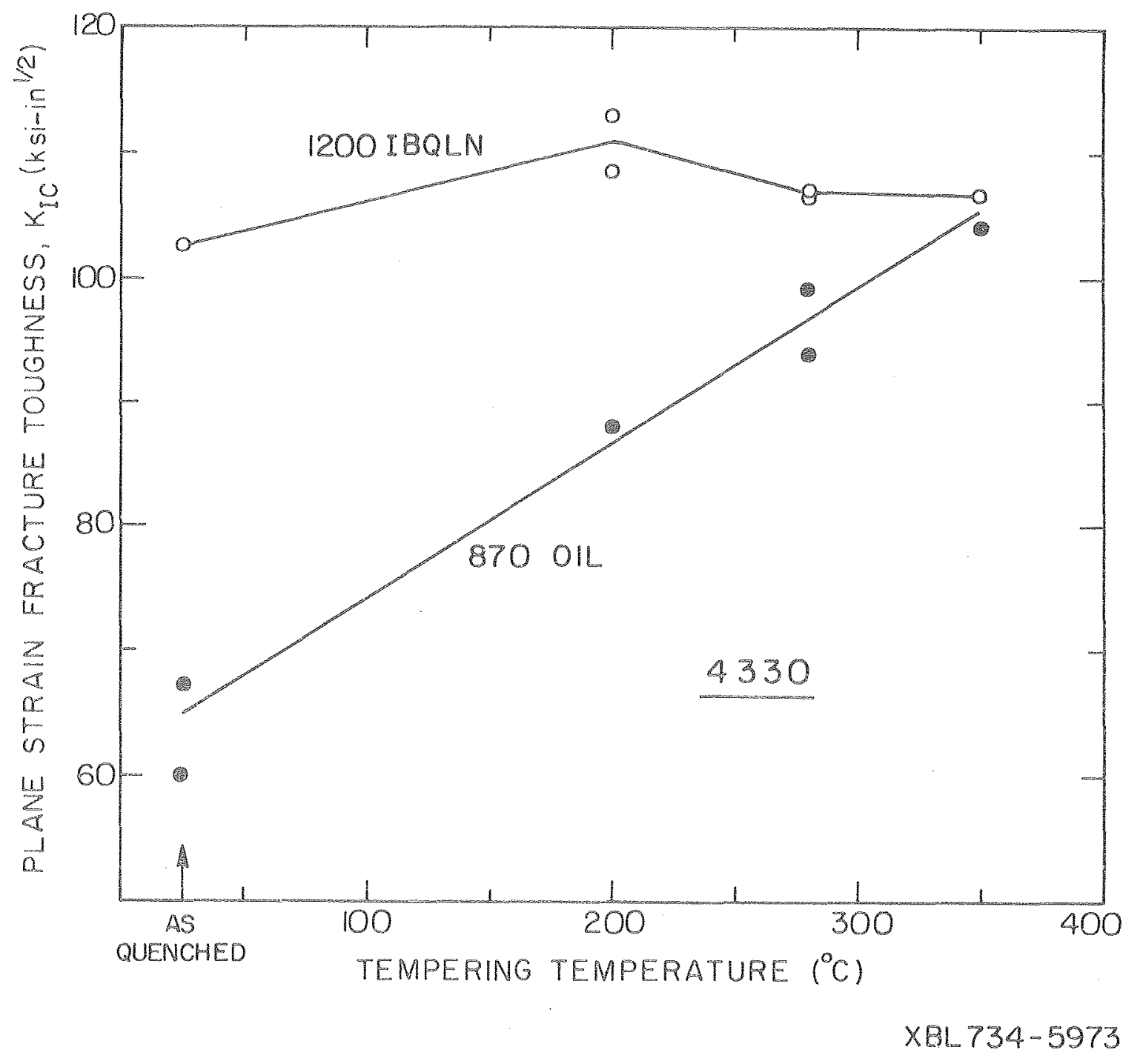

Figure 11. 


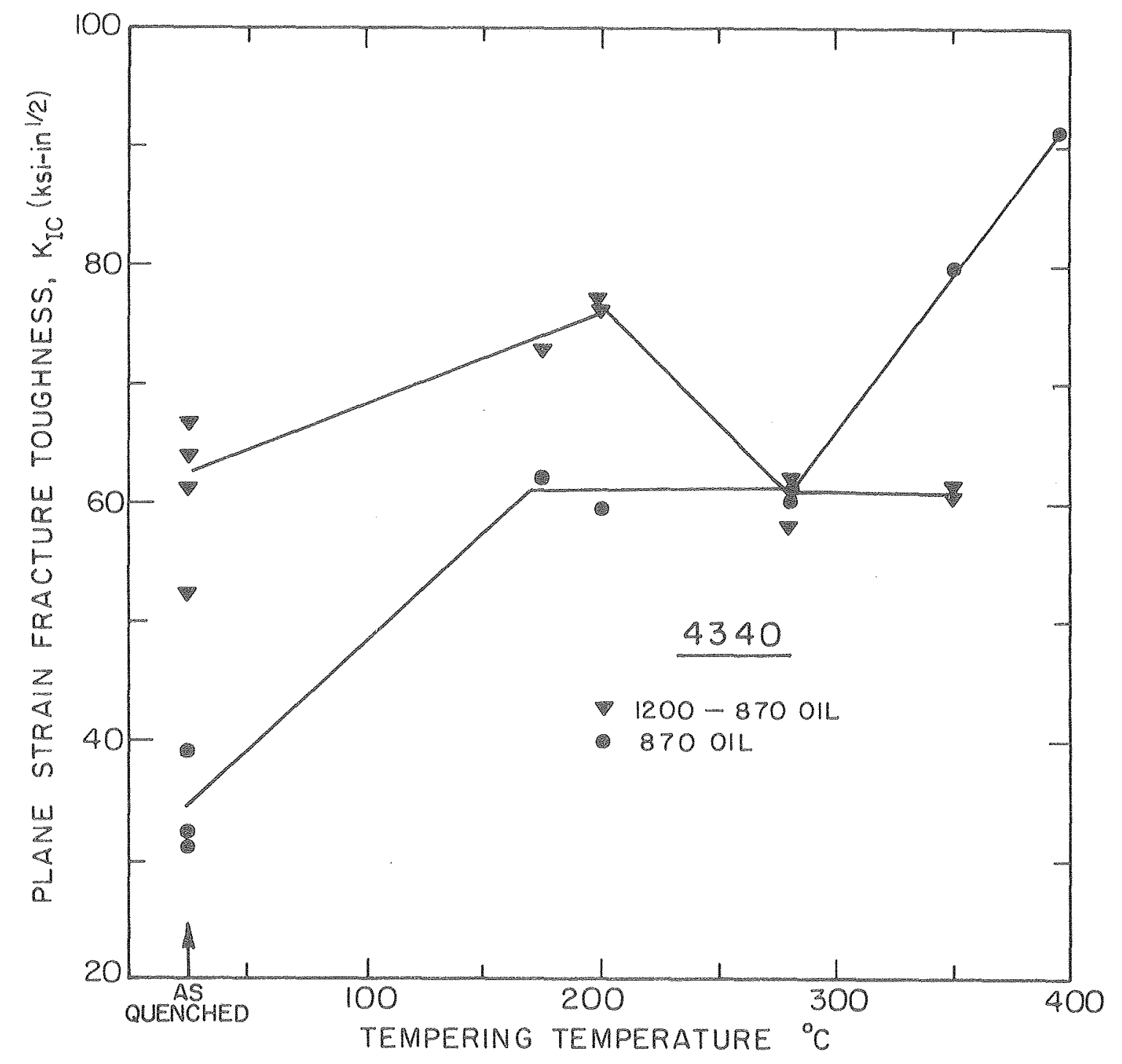

XBL 734-5974

Figure 12 . 

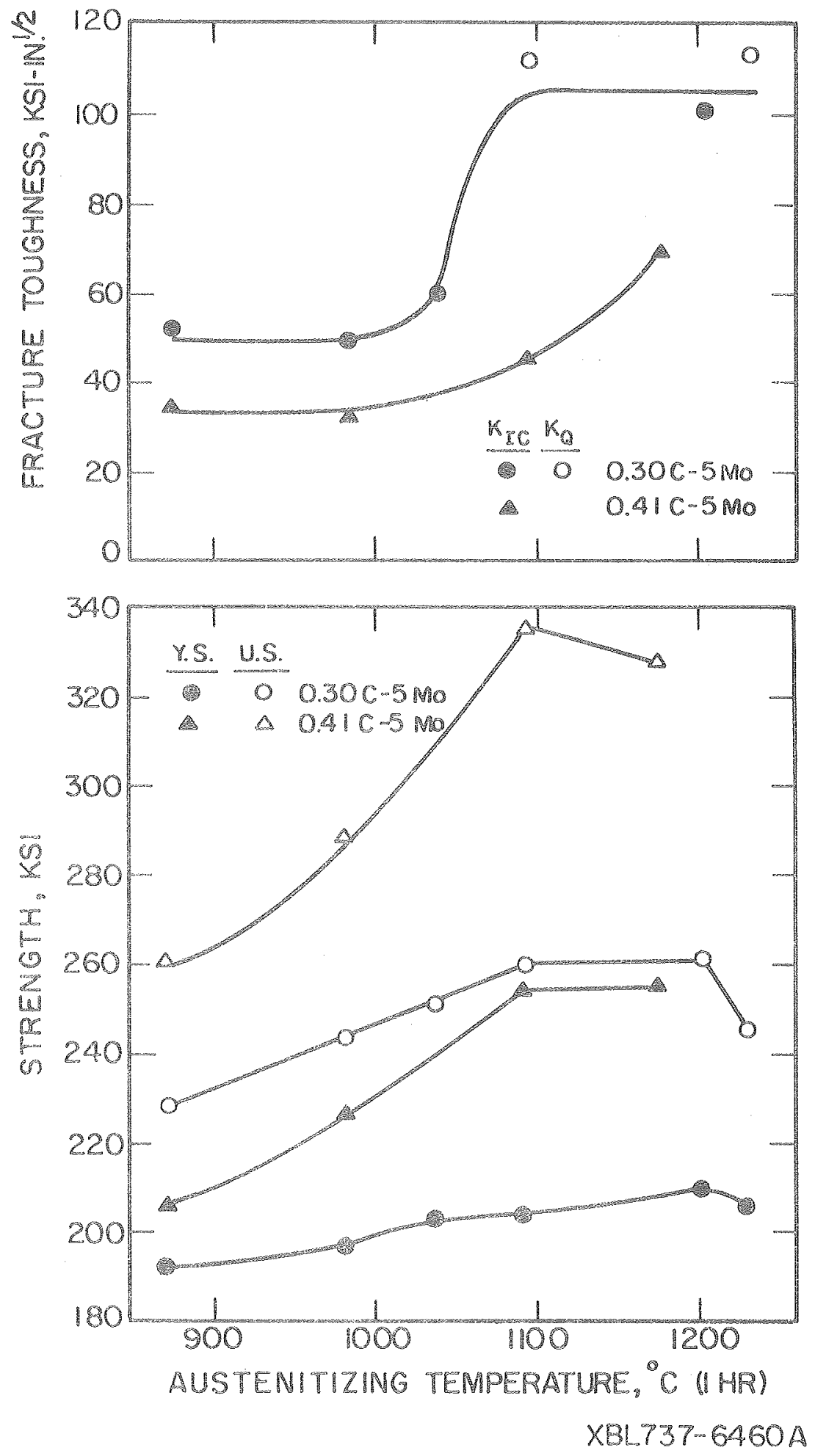

Figure 13 . 


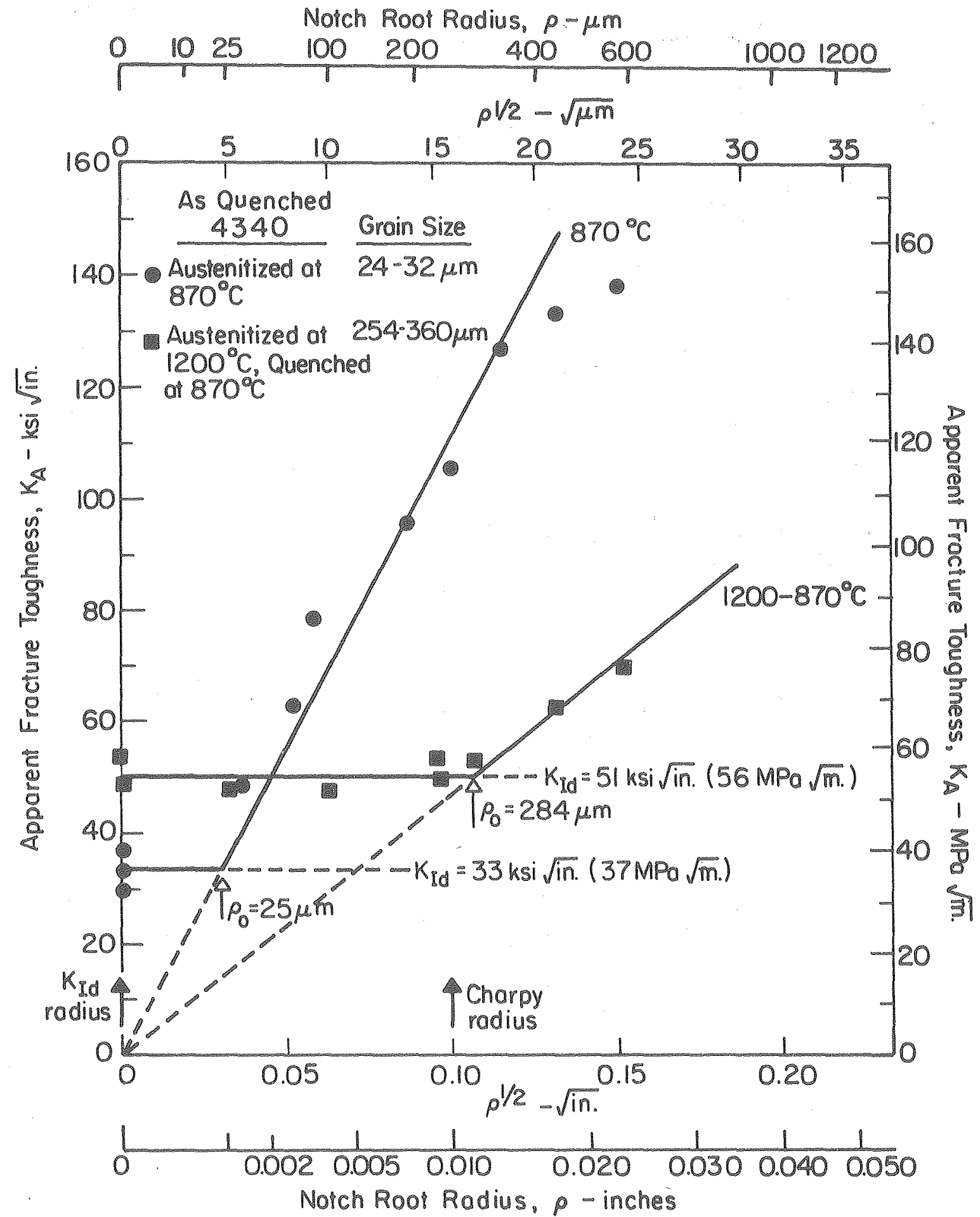

XBL 758.6995

Eigure 14 . 


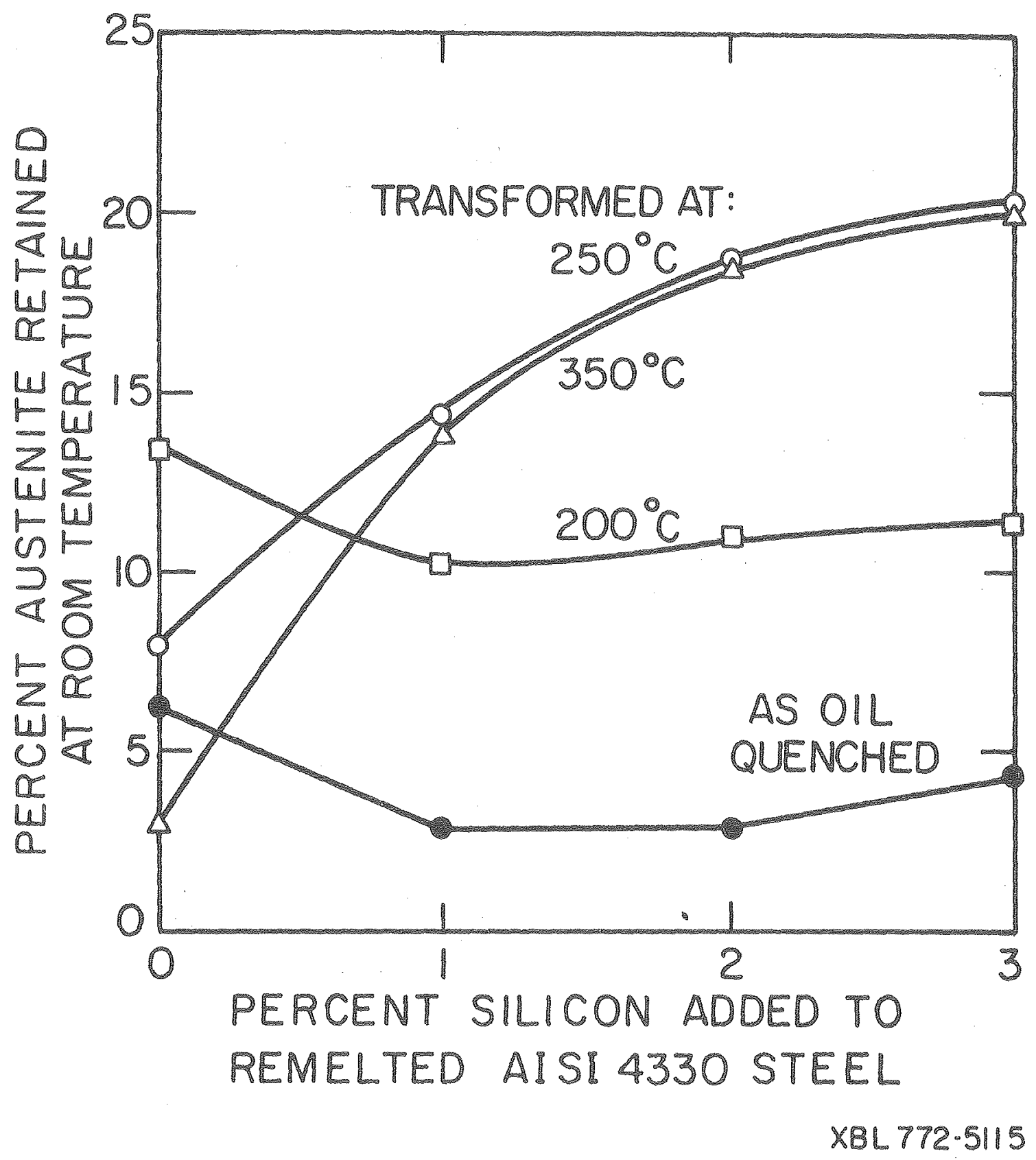

Figure 15. 


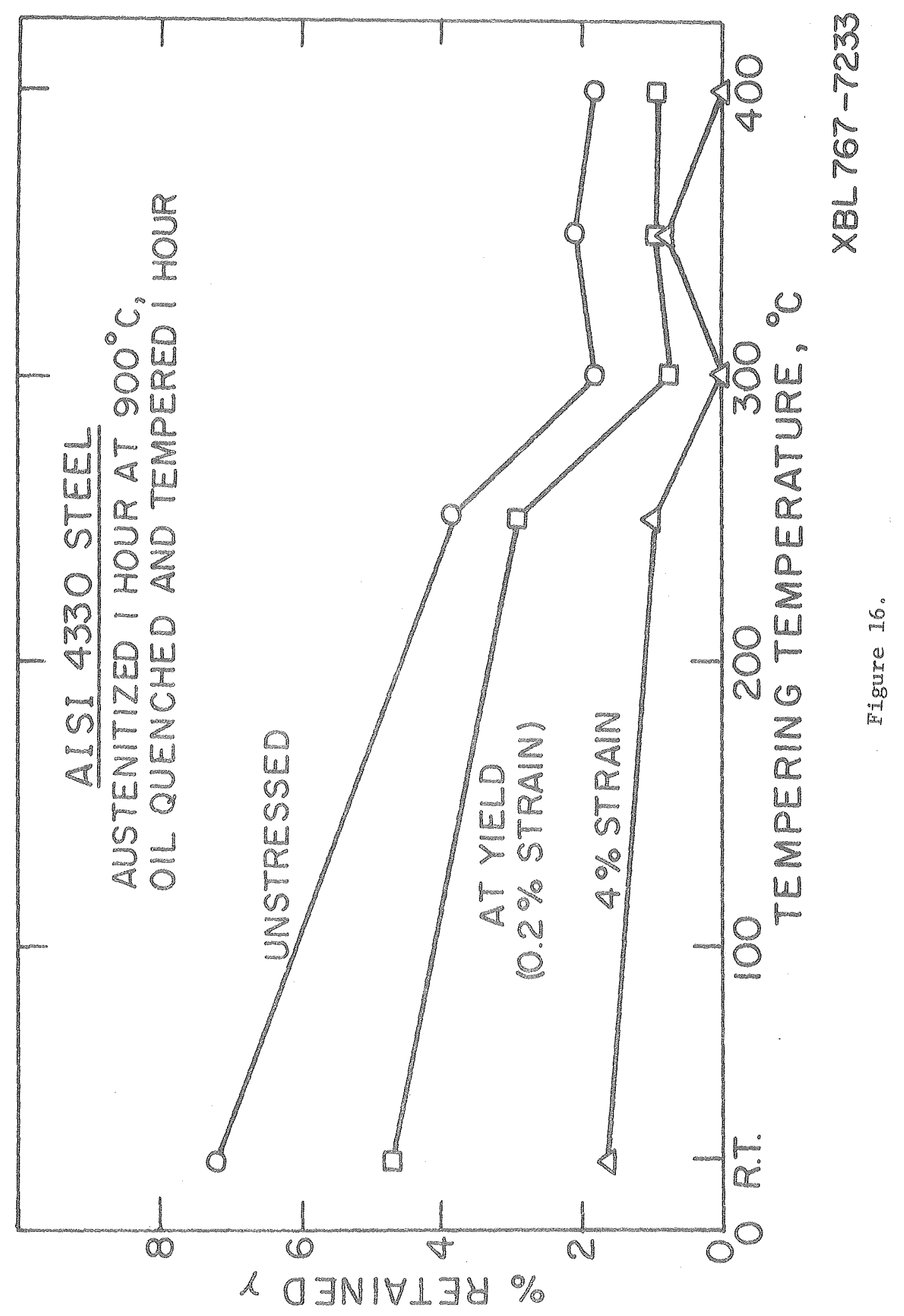




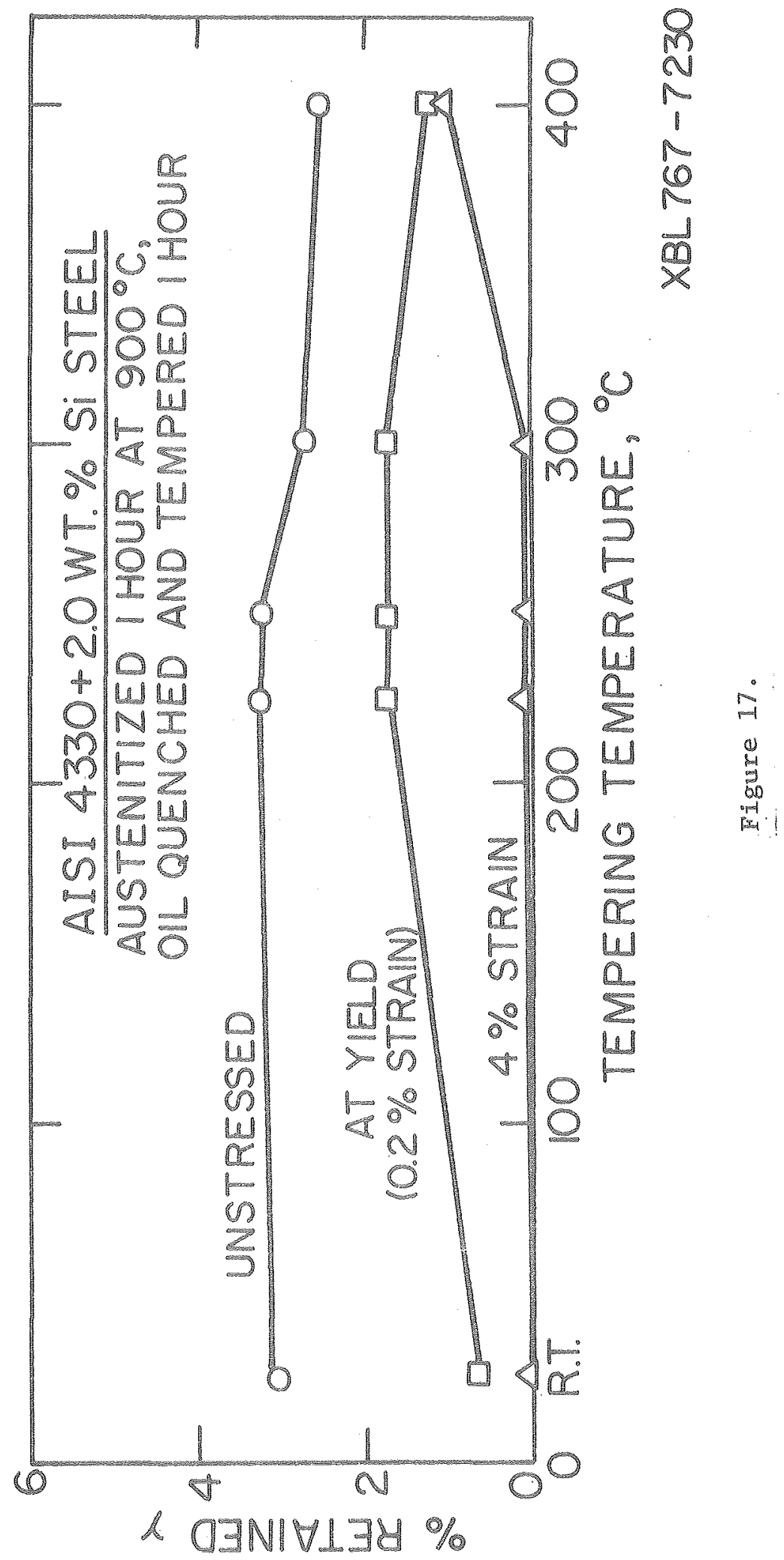



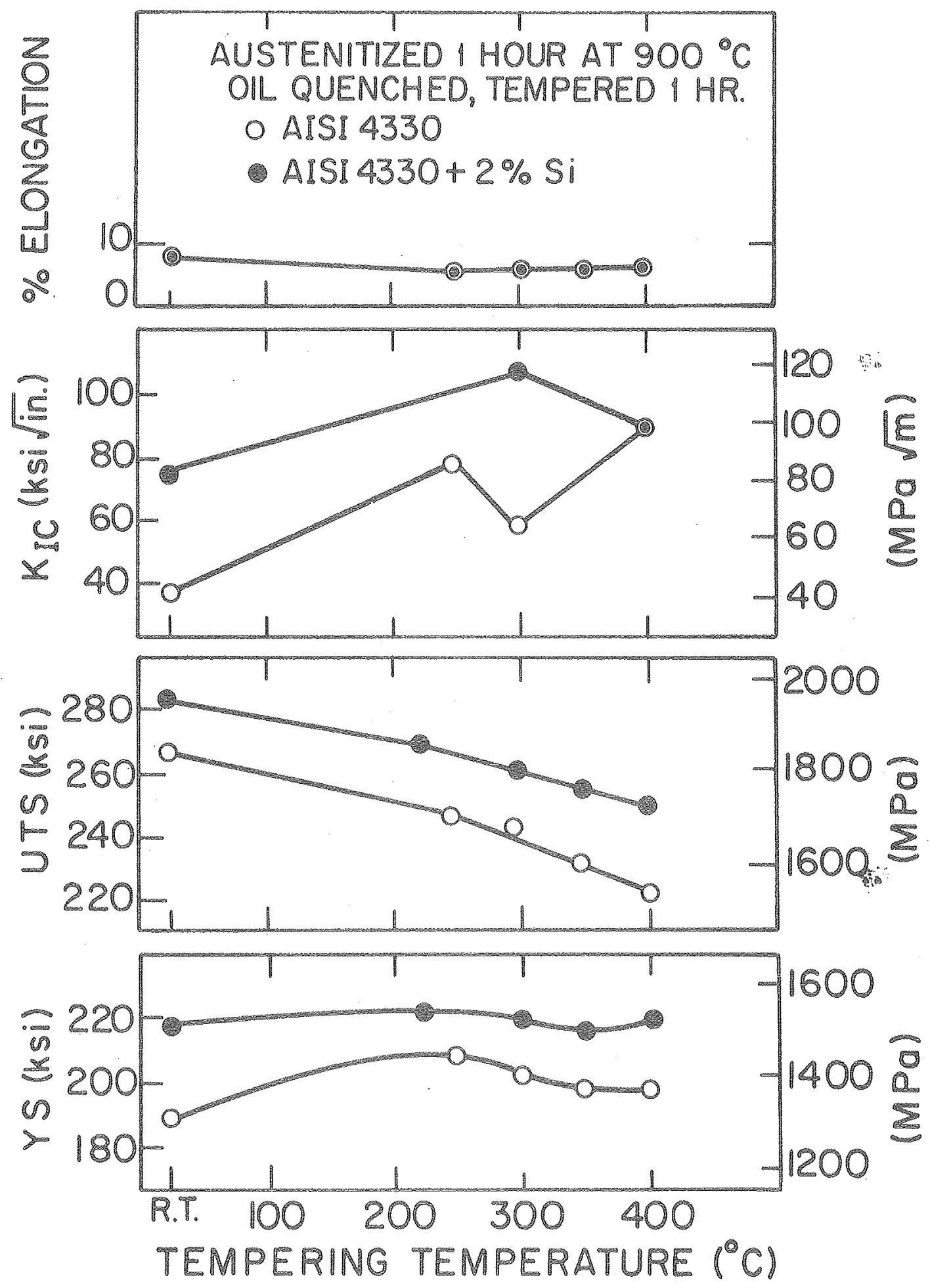

Xㄴ.72.5116

Figure 18 . 


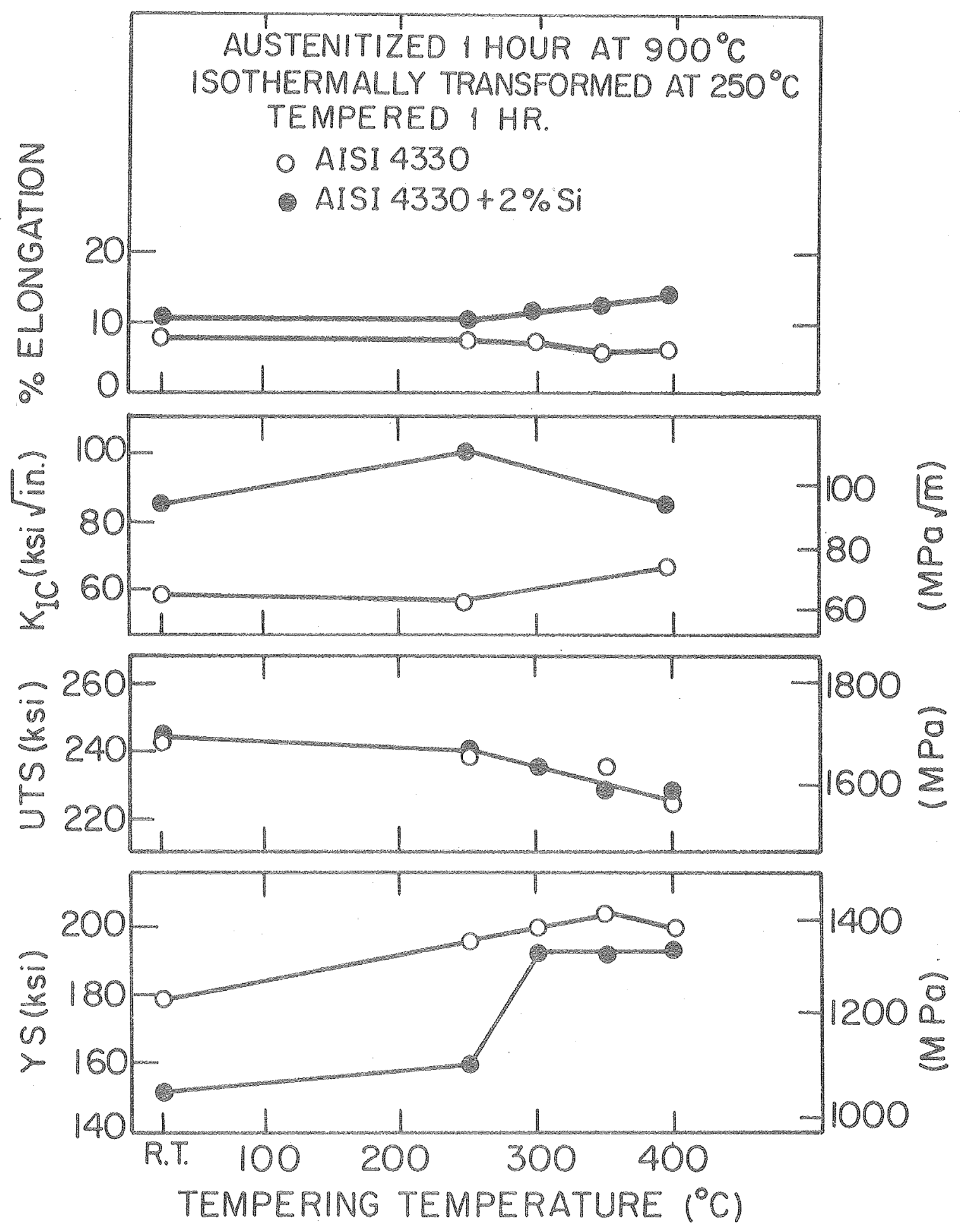

XBL.772-5117

Figure 19. 

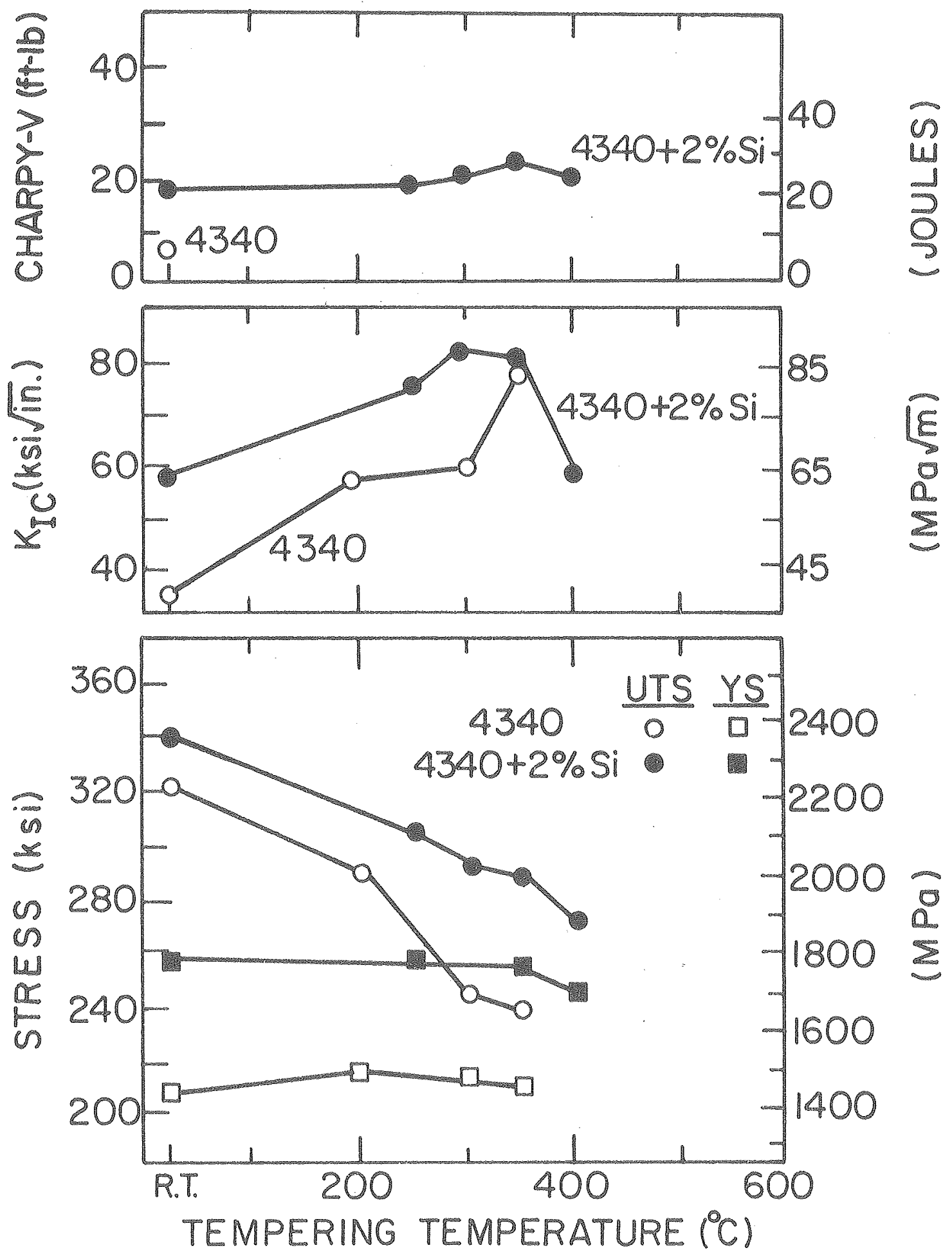

Figure 20.

XBL772.5118 


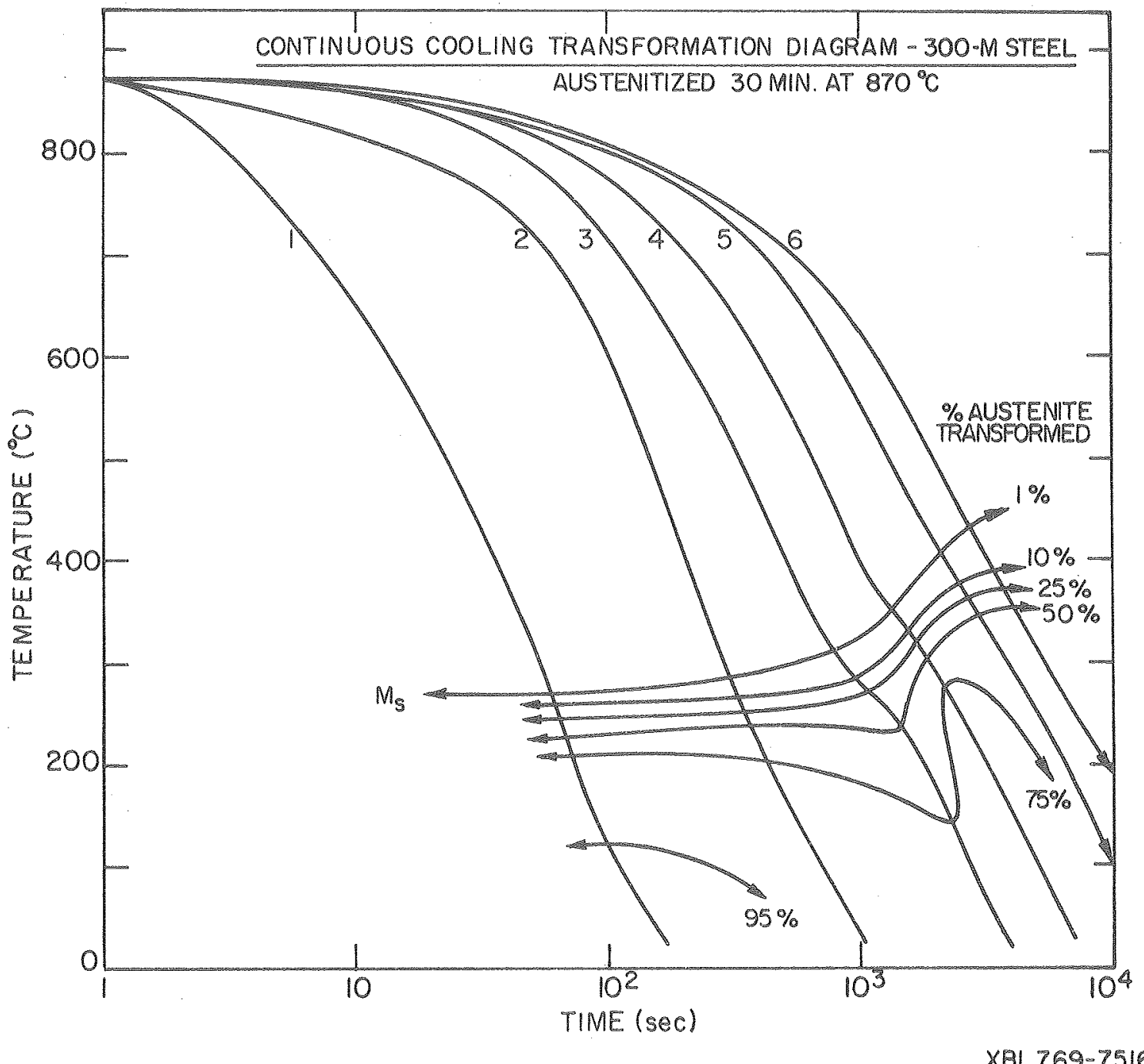

Figure 21. 


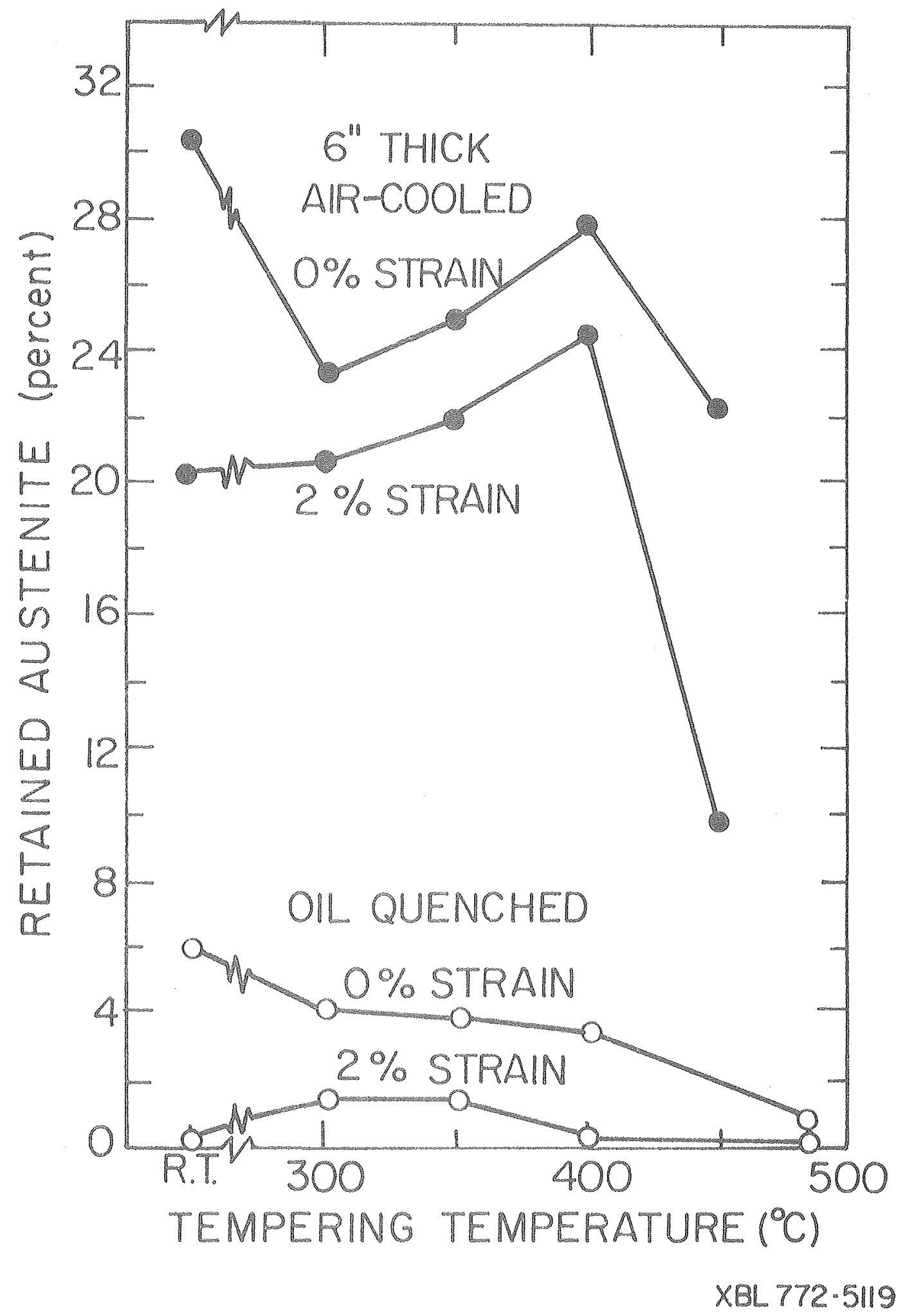

Figure 22. 

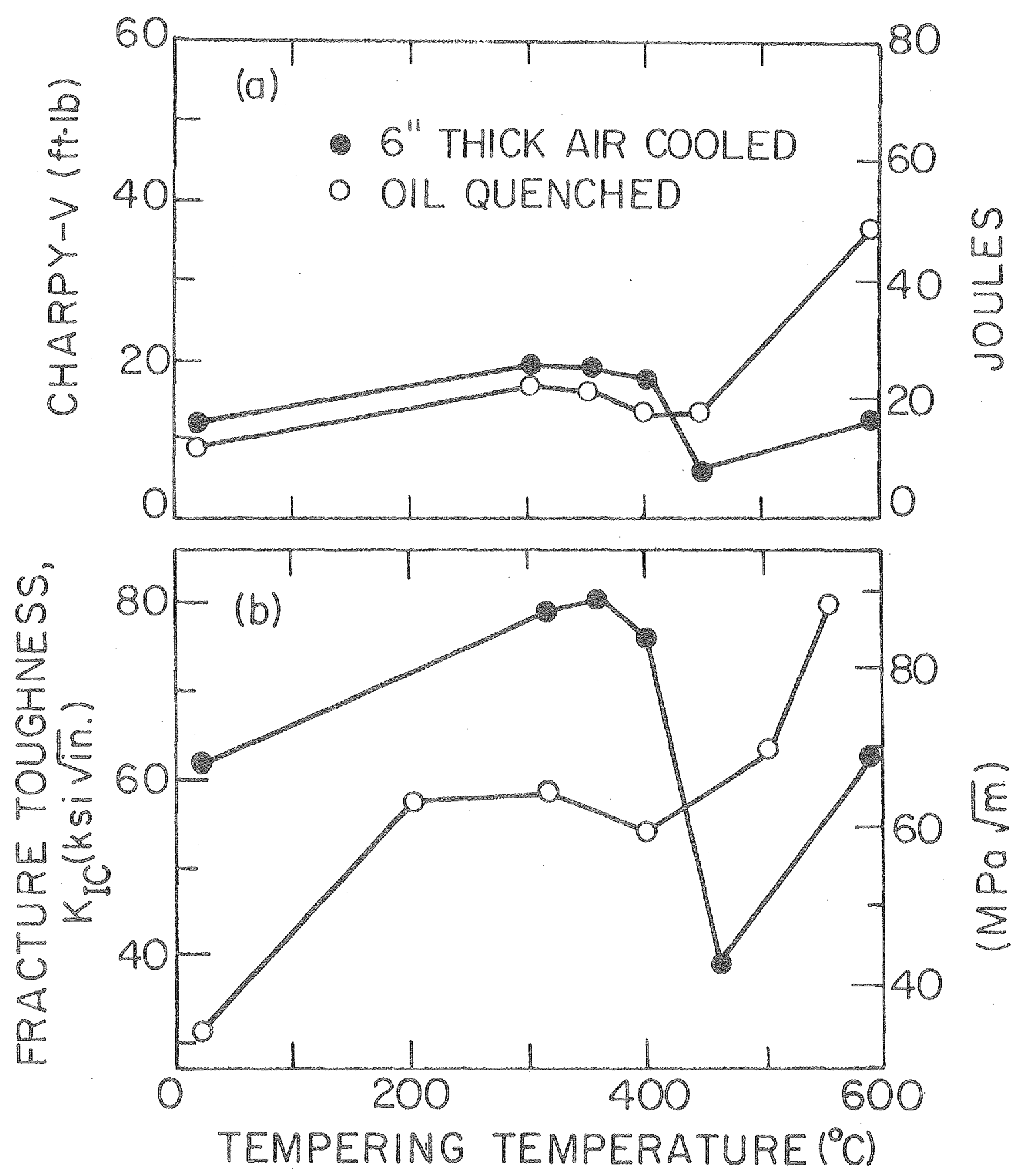

XBL772-5120

Figure 23. 
$00: 0 \cdot 70,4 \% 1$

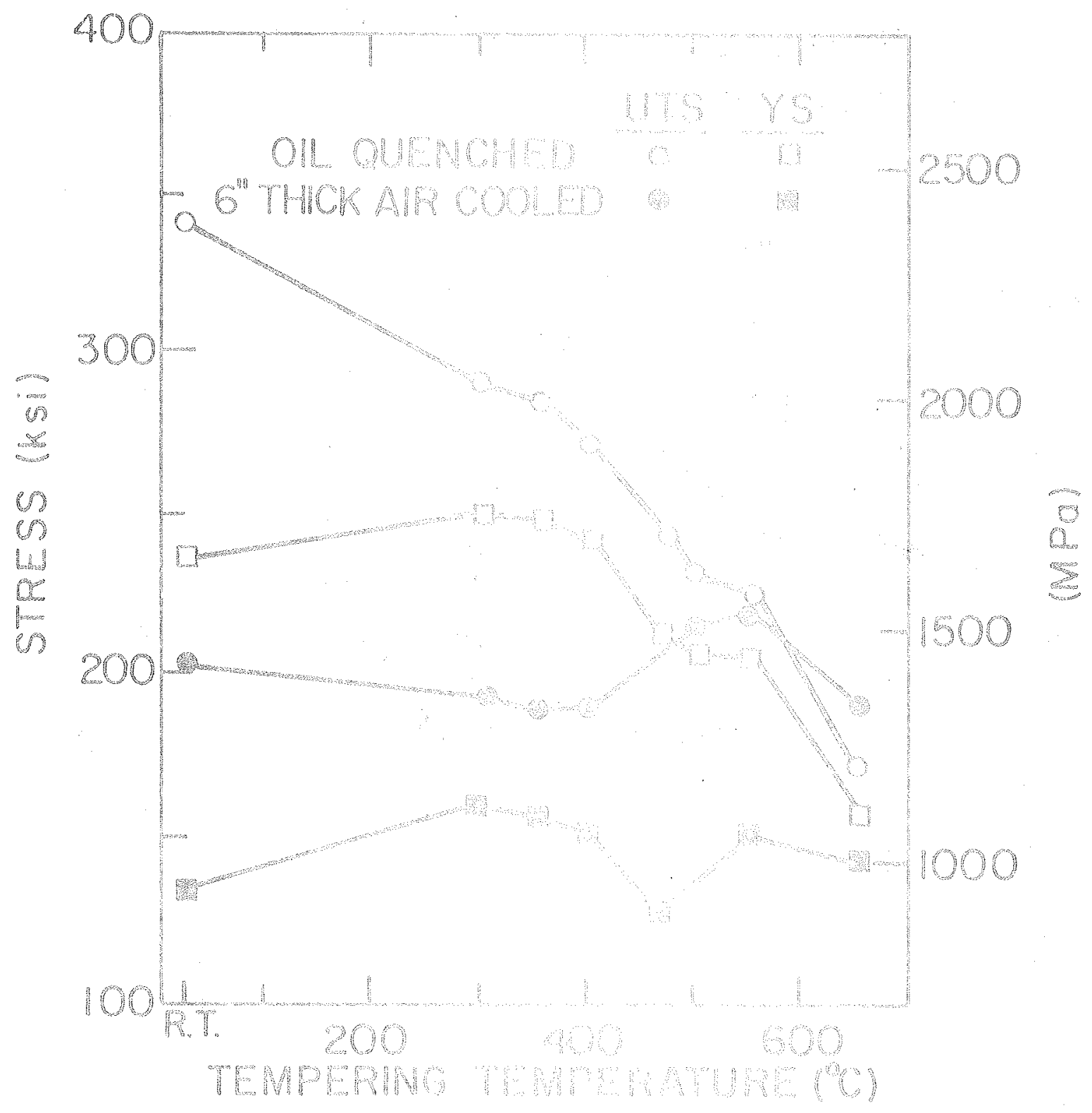

X6L.772.5121 


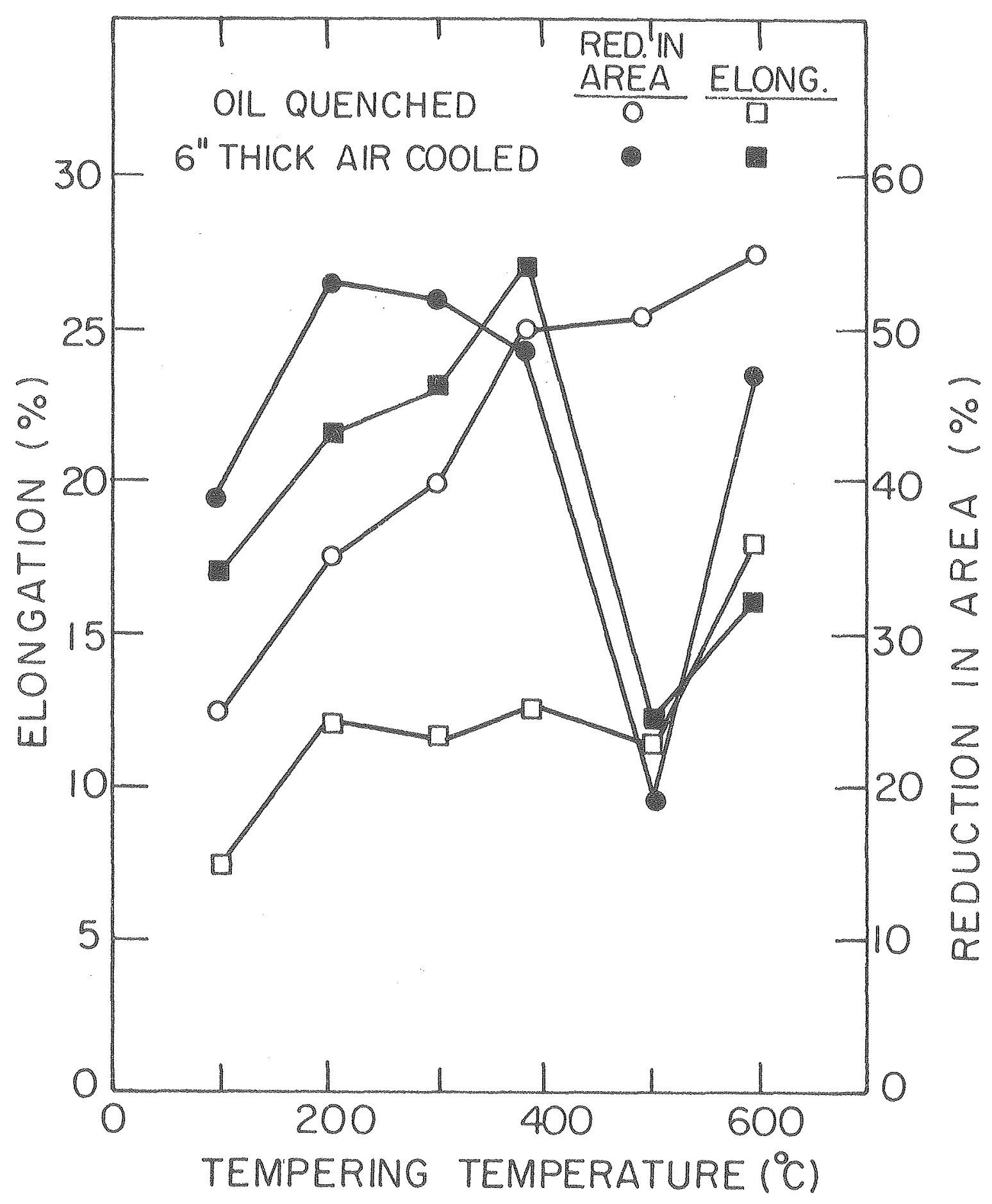

XBL772-5122

Figure 25 . 


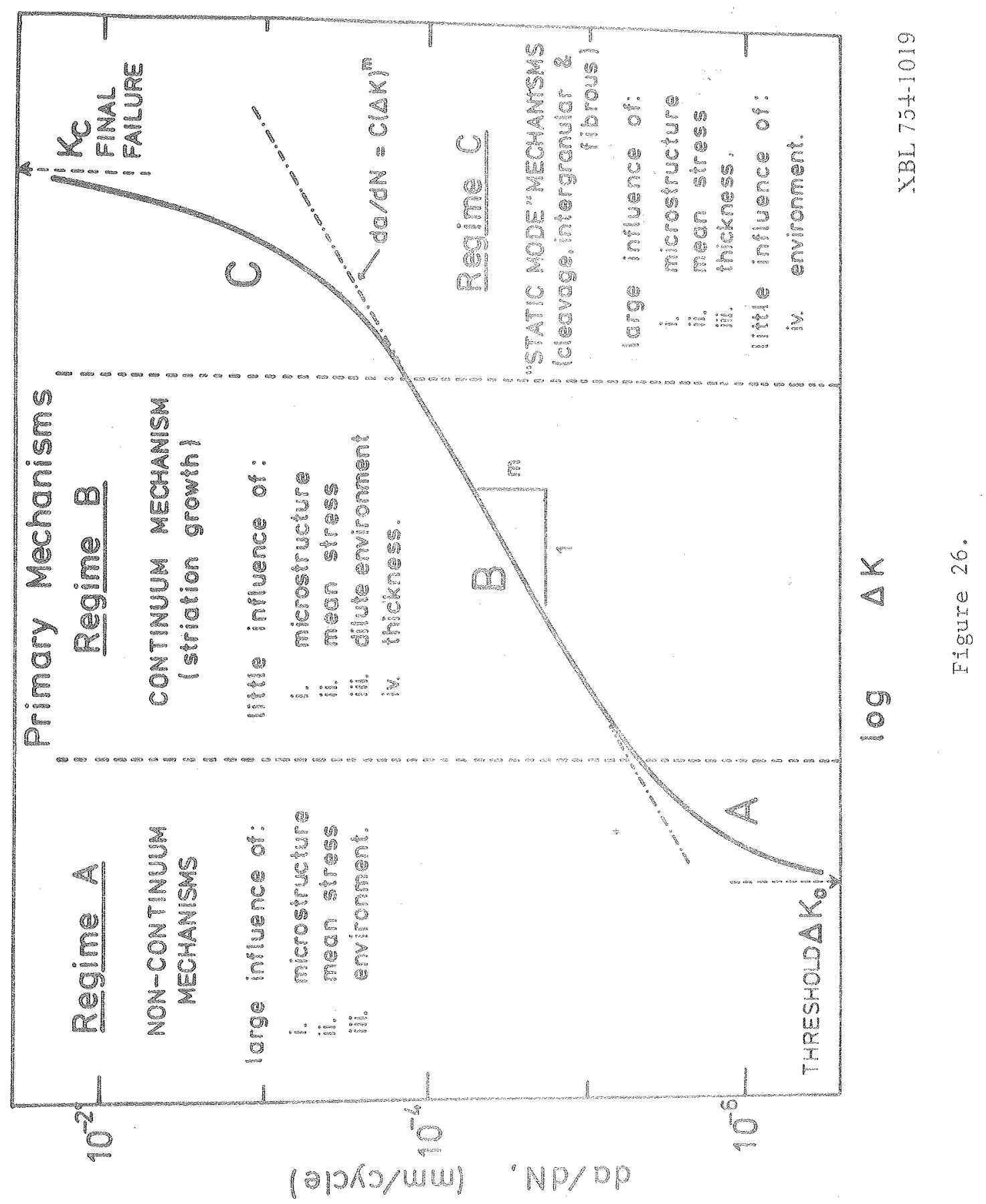




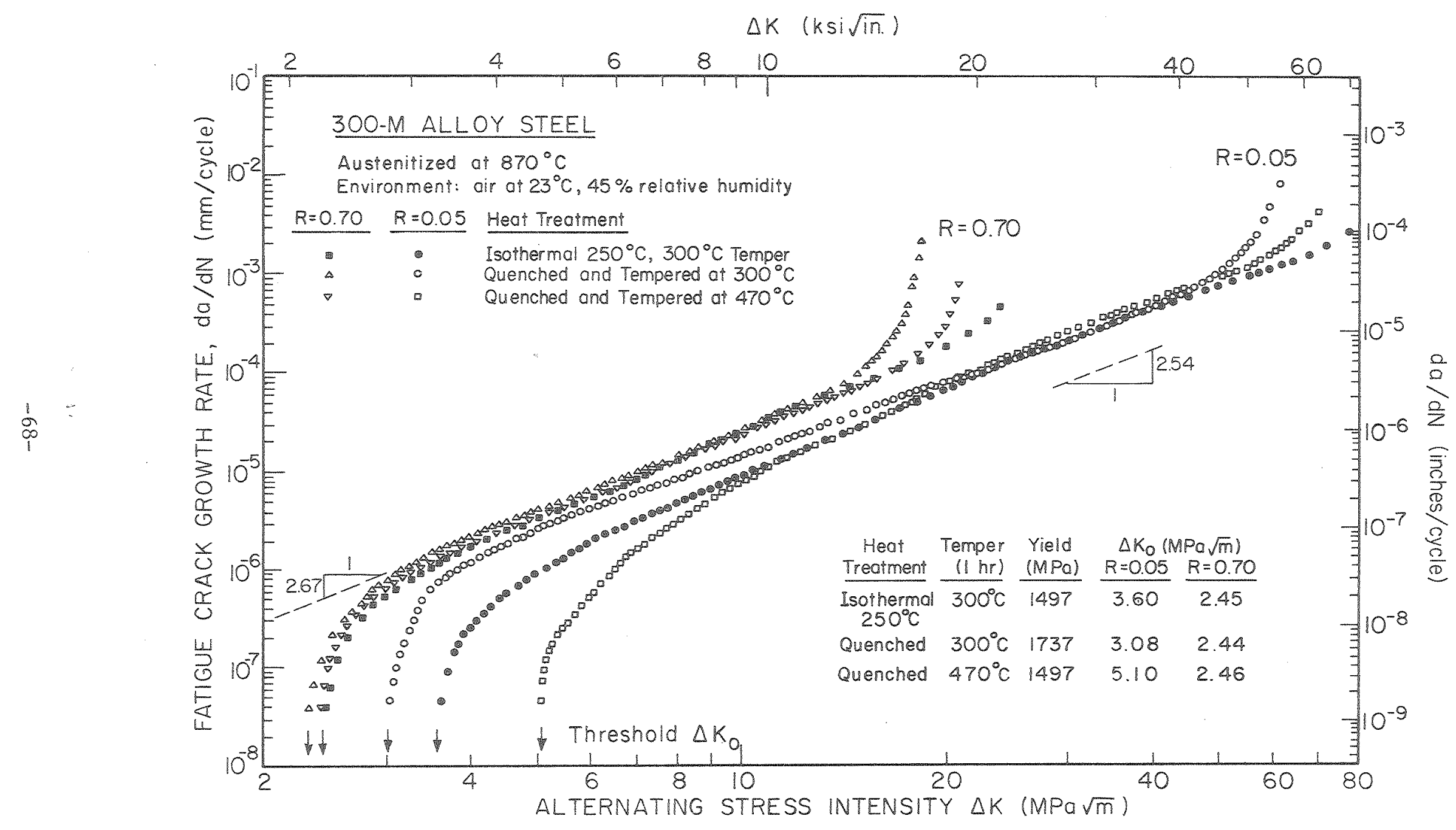

XBL766-7083

Figure 27. 


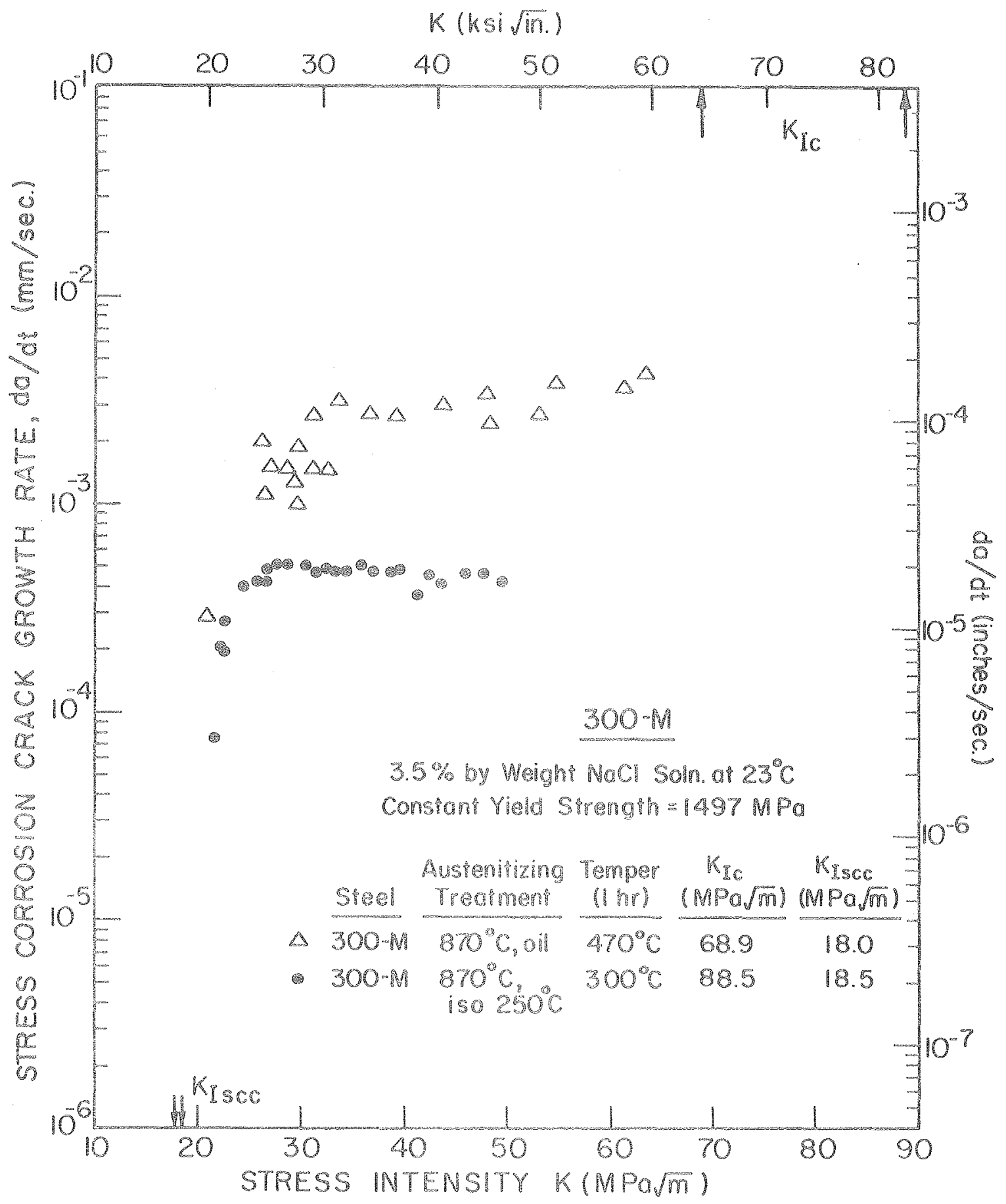

XBL7610-7628

Figure 28. 


\section{REFERENCES}

1. E. S. Davenport and E. C. Bain, Trans. AIME, 1930, vo1.90, p. 117.

2. Physical Properties of Martensite and Bainite, The Iron and Steel Institute, 1965, Special Report 93, p.211.

3. Transformation and Hardenability in Steel, Climax Molybdenum Co. of Mich., Symposium, 1967, p. 212.

4. Decomposition of Austenite by Diffusional Processes, Interscience, 1962.

5. H. I. Aaronson, The Mechanism of Phase Transformation in Crystalline Solids, Institute of Metals Monograph Report, 1969, vol. 33, p. 270.

6. J. M. Oblak, R. H. Goodenow, and R. F. Hehemann, Trans. Met. Soc. AIME, 1964 , Vol. 230, p. 258.

7. R. H. Goodenow, S. J. Matas, and R. F. Hehemann, Trans. Met. Soc. ATME, 1963, Vo1. 227, p. 651.

8. R, F. Hehemann, K. R. Kinsman, and H. I. Aaronson, Met. Trans., 1972, vol. 3, p. 1077.

9. R. Honeycombe, and F. Pickering, Met. Trans., 1972, vo1. 3, p. 1099.

10. G. R. Srinivasan and C. M. Wayman, Acta Met., 1968, vol. 16, p. 621.

11. R. F. Hehemann, Phase Transformations, A.S.M., 1970, p. 409.

12. The Making, Shaping, and Treating of Steel, U.S. Steel Co., Pittsburgh, Pa., 1971, p. 1133.

13. B. G. Reisdorf, Trans. AIME, vol. 227, 1963, p. 1334.

14. G. S. Anse11 and E. M. Breinan, Trans. ASM, vo1. 58, 1965, p. 110.

15. J.K. Stanley, Electrical and Magnetic Properties of Meta1s, ASM, Metals Park, Ohio, 1963.

16. G. R. Speich, Met. Trans., vol. 245, 1969, p. 2553.

17. C. S. Roberts, B. L. Averbach, and M. Cohen, Trans. ASM, vo1. 45, 1953, p. 576.

18. P.H. Zajchowski, M。S. Thesis, Department Materials Science and Engineering, University of California, Berkeley, August 1974.

19. G. Kurdjumov, and L. Lyssak, J. Iron and Steel Inst., vol. 156, 1947, p. 29.

20. S. Fletcher and M. Cohen, Trans. ASM, vol. 32, 1944, p. 333. 
21. B. L. Averbach and M. Cohen, Trans. ASM, vol. 41, 1949, p. 1024.

22. C. S. Roberts, B. L. Averbach, and M. Cohen, Trans. ASM, vo1. 45, 1953, p. 576.

23. M. Mentser, Trans. ASM, Vo1. 51, 1959, p. 517.

24. J. Crangle and W. Sucksmith, J. Iron and Steel Inst., vol. 163, 1951, p. 141.

25. F. E. Werner, B. L. Averbach, and M. Cohen, Trans. ASM, vol. 49, 1957, p.823.

26. K. H. Jack, J. Iron and Sceel Inst., vo1. 169, 1951, R. 26.

27. H.W. King and S. G. Glover; I. Iron and Steel Tnst., vol. 193, 1959, p. 123.

28. B. S. Lement, B. L. Averbach, and M. Cohen, Trans. ASM, vol. 46, 1954, p. 851.

29. D. M. Teague and S.T. Ross, Pxoc. ASTM, vo1. 55, 1955, p. 590.

30. P.M. Kel1y and J。Nutting, J. Tron and Steel Tnst., vol. 197, 1961, p. 199.

31. A. M。Turka1o, Trans. ASM, vol. 54, 1961, 344.

32. A. E. Austin and C.M. Schwartz, Broc, Asm, vol. 52, 1952, p. 592.

33. F. G. Wlson and $W . S$ owen, J. Iron and Steel Inst.. June 1965, p. 590.

34. A. M. LIop1s, Ph.D. Thes1s, Department of Materials Science and Engineering, University of California, Berkeley, June 19\%.

35. P. Vasudevan, I. W. Graham, and H. J. Arom, I. Iron and Steel Inst., 1958, vol. 190, p. 386.

36. S. V. Radcliffe and E. C. Rollason, J. Tron and Sseel Tnst. 1959, vol. $191, p .56$.

37. J. S. White and W. S. Owen, I. Iron and Steel Inst., 1960, vol. 195, p. 79.

38. A. E. Austin, and C.M.Schwatcz, Proc. ASTM, 1952, vo1. 52, p. 592.

39. R. H. Goodenow, S. J. Matas, and R. F. Hehemann, Trans. ATME, vol. 227, $1963, p .651$.

40. T. Ko, and S. A. Cottre11, J. Tron and Steel Inst., 1952, vol. 172, p. 307.

41. G. R. Spetch and Mo Cohen, Trans. ATME, 1960, vol. 218, p. 1050.

42. R. H. Goodenow, R. H. Barkalow, and R. H. Hehemann, Bainite Transformations In Hypoeutectold Steels, Physical properties of Martensite and Bainite, Special Report 93, The Iron and Steel Tnstitute, 1965, p. 135. 
43. F. P. Pickering, The Structure and Properties of Bainite in steels, Transformation and Hardenability in Steels, Symposium by Climax Molybdenum Co. and Univ. Mich, 1967. p. 109.

44. Atlas of Isothermal Transformation Diagrams, U. S. Steel Co., 1951.

45. Phase Transformation Kinetics and Hardenability of Mediumoarbon Alloy Steels, CIImax Molybdenum Co., 1972.

46. B. N, P. Babu, M. S. Bhat, E. R. Parker, and V. F. Zackay, Met. Trans., 1976, vol. 7A, p, 17.

47. P. Vasudevan, L. W. Graham, and H. J. Axon, J. Iron and Steel Inst., 1958, vol. 190, p. 386.

48. S. V. Radcliffe and E. C. Rollason, J. Iron and Steel Inst., 1959, vol. $191, p .56$.

49. S. J. Matas and R. F. Hehemann, Trans. Met. Soc. AIME, 1961, vo1. 221, p. 179.

50. A. Schrader and F. Wever, Arch. Eisenhuttenwo, 1952, vol. 23, p. 489.

51. H. Modin and S. Modin, Abstract Rev. Met., 1956, vol. III, p. 173.

52. K. Tsuya, J. Mech. Lab., Japan, 1956, vol. 2, p. 20.

53. G. R. Spejch, Decomposjtion of Austenite by Diffusional Processes, Met. Soc. AIME, 1960, P. 353.

54. J. M. Oblak, R. H. Coodenow, and R.F.Hehemann, Trans. Mec. Soc. AIME, 1964, vol. $230, p=258$.

55. P.M. Kelly, and J. Nutting, J. Iron and Steel Inst., 1961, vol. 197, p. 199.

56. D. N. Shackleton and P.M. KeIJy, Physjcal Properties of Martensite and Bainite. Special Report 93, Tron and Steel Institute, 1965, p. 126.

57. J.M. Oblak and R. H. Hehemann, Transfomation and Uaxdenability in Steels, Climax Molybdenum Co of Michigan, 1967, p. 15.

58. H. I. Aaronson, Decomposition of Austenite by Diffusiona1 Processes, ed. V. F. Zackay and H. I. Aaronson, Tnterscience, New York, 1962, p. 387.

59. R. F. Uehemann and A. R. Trolano, J. of Metals, Trans. ATME, Nov。 1954, p. 1272.

60. K. J. Trvine and F. B. Pickering, Physical Propexties of Martensite and Bainite, Special Report 93, Iron and Steel Institute, 1965, p. 110.

61. G. Thomas, Iron and Steel International (England), Oct. 1973, p. 459.

62.W.S. Owen, Trans. ASM, vol. $46,1954, \mathrm{p}, 824$.

63. R. B. Banerjee, J. Tron and Steel Insto. Feb. 1965, p. 166.

64. Der-Hung and G. Thomas, Trans. ASM, vol. 62, 1969, p.659. 
65. R. D. Goolsby, W. E. Wood, E. R. Parker, and V. F。 Zackay, Electron Microscopy. and Structure of Materials, University of California Press, Berkeley, 1972, p. 798 .

66. E. B. Kula, and A. A. Ancil, I. Materials, JMLSA, vo1.4, No. 4, Dec. 1969, p. 817 .

67. L. J. Klingler, W。 J. Barnett, R. P. Frohmberg, and A. R. Troiano, Trans. ASM, vol. 46, 1954, p。1557.

68. ASTM Standards, E399-74, Philadelphia, 1974.

69. T. Tom, Ph.D.Thesis, Department Materials Science and Engineering, University of California, Berkeley, Sept. 1973.

70. G. Y. Lax, W. E. Wood, R. A. Clark, V.F。 Zackay and E。 Ro Parker, Met. Trans., vol. 5, 1974, p. 1663.

71. D. Dulieu, Discussion of papex by V.F。Zackay, E. R. Parker, and W。E。 Wod, Proc. Thixd International Conference on the Strength of Metals and Alloys, Instrute of Metals and Iron and Steel Institute, Cambridge, England, vol. 2, Aug. 1973, p. 383.

72. R. 0. Ritchie, B. Francis, and W. L. Server, Lawrence Berkeley Laboratory Report 4125, Sept. 1975 (Submitted to Met. Trans.).

73. T. R.Wilshaw, C. A. Rau, and A. S. Tetleman, Eng. Fracture Mech., vol. L, $1968, \mathrm{p} .191$.

74. J. Malkin and A. S. Tetleman, Eng. Fracture Mech., vol. 3, 1971, p. 151.

75. P. T. Heald, G. M. Spink, and P. J. Worthington, Mat. Sci. Eng., vo1. 10, $1972, p \cdot 129$.

76. G. Kohn, PhoD. Thesis, Department of Materials Science and Engineering, University of California, Berkeley, Nov. 1976.

77. S. K. Das and Go Thomas, Txans. ASM, vol, 62, 1969, p.659.

78. G. Thomas and S.K. Das, J. Iron and Steel Institute, vol. 209, 1971, p. 801.

79. D. Webster, Trans. ASM, vo1.61, 1968, p.816.

80. So Jin, D. Huang, and J.W. Morris, Jro, Met. Trans., vol. 7A, 1976, p.63\%.

81. C. A. Pamp1110 and H.W. Paxton, Met. Trans., vol. 3, 1972, p. 2895.

82. D. Bhandarkar, V.F. Zackay, and E. R. Parker, Met. Trans., vo1. 3, 1972, p. 2619.

83. D. Fahr, Met. Trans., Vo1.2, 1971, p. 1883.

84. W.W.Gerberich, P. Lo Hemmings, and V. F. Zackay, Met. Trans., vo1.2, 1971, p. 2243 .

85. M. F. Car1son, B. V. N. Rao, R. O. Ritchie, and G. Thomas, Lawrence Berkeley Laboratory Report 5111, Berkeley, Ca。April 1976. 


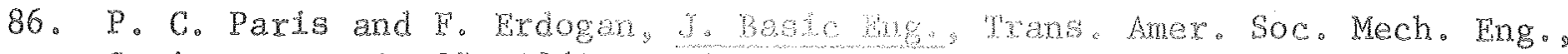
Series D., vol. 85, 1963, p. 528,

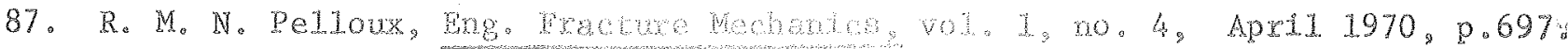

88. C. E. Richards and T. G. Whotey, tre tracture Mech, vol. 4, no. 4. Dec。1972, p。951.

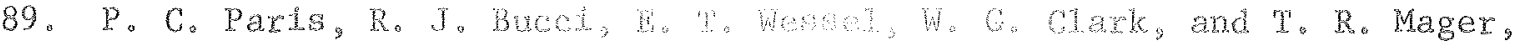
Stress Analysis and Crowth of Grecte. ANM, BTH 513, ASTM, 1972, p. 141.

90. R. A. Schmidt and P. C. Bars, Bcogres th Wow crowth and Fracture Toughness Testing, ASTM, STR 536, ACMT, $1973,0 \%$

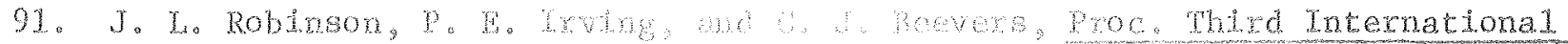


Dusseldore, Aprit 1973, wol. V, poper y.3.

92. R. O. Rtchle, and J. H. Knote, Acta Mcte, wol. 21, no. 5, May 1973, p.639.

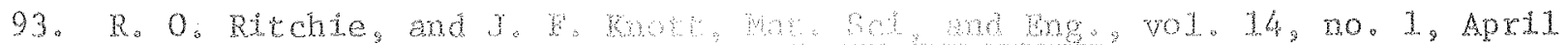
$1974, p=7$.

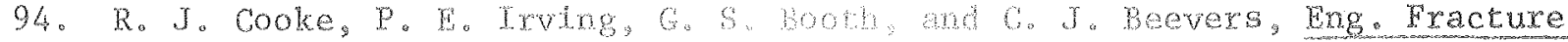
Mech., vol. 7, no, 3 , March 1975, p. 69.

95. B. O. Ritchie, Broc. Hourth Thtemathoul Conforence on Fracture, Watexloo Canada, June 1977 (Report No. Th, 5188 , Gawrence Berkeley Lab. University California, Berkeley, Jume 1976 .

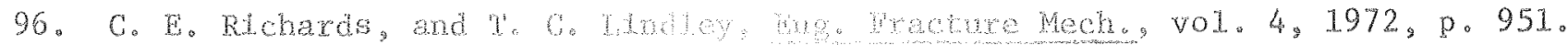

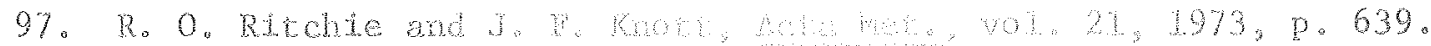

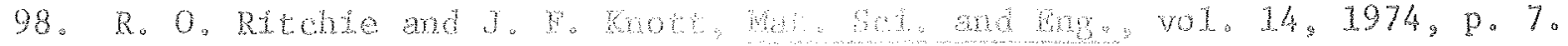

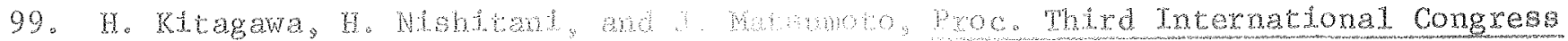
on Tracture, Mutch, $19 \%$, Paper $\forall-1 / 1 /$.

100. J. L. Robinson, and C.J. Reevers, Metal Sel, I., vol. 7, 1973, p. 153.



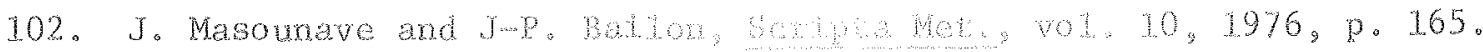

103. R。 O. Ritchie, J. The Mat ant Wech ("wans ASME [X]) 1977 (in press)。

104. M. KIesnil and P. Lukas, Mec set ant mo, vol, 9, 1972, p. 231.

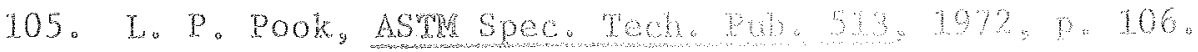


ASTM Spec, Publ. $513,197 \%, 0,127$ 
167. P.C. Paris, R. J. Bucci, E. T. Wesse1, W. G. Clark, and T. R. Mager, ASTM Spec. Tech. Pub. 513, 1972, p. 141.

108. R. J.Bucci, W. G. Clark, and P.C. Paris, ASTM Spec. Tech. Pub. 513, 1972, p. 177

109. A. J. McEvily and J. Groeger, Proc. Fourth International Conference on Fracture, Waterloo, Canada, June 1977.

110. R. 0. Ritchie, Proc. Fourth International Conference on Fracture, Waterloo, Canada, June 1977 (Univ. Calif. LBL Report No. 5188, June 1976)。

111. R. O. Ritchie, Met. Trans. A, 1977 (in press) (Univ. Calif. LBL Report No. 5498, Oct. 1976).

112. M. Klesni1, and P. Lukas, Eng. Fracture Mech., vol.4, 1972, p. 77.

1.13. J.A. Feeney, J。C. McMillan and R.P.Wei, Met. Trans., vo1. 1, 1970, p. 1741.

114. R. J. Cooke, P. E. Irving, G. S. Booth, and C. Jo Beevers, Eng. Fracture Mech., vol. 7, 1975, p.69.

115. R. O. Ritchie, Invited Paper for The Metals Society Conference FATIGUL 1977 , Cambridge, United Kingdom, March 1977.

116. R. O. Ritchie, submitted to J. Eng. Mat. and Tech., Trans. ASME, Series [il], 1977. (Univ. Ca1if. LBL Report No.5496, Oct. 1976).

117. D. Webster, AFC, Boeing Document D6-23973, The Boeing Co, Seattle, Wash., June 1969.

118. H. H. Uhlig, Corrosion and Corrosion Control, Second ed. John Wiley and Sons, New York, 1971.

119. R. A。 Oriani and P. H. Jospehic, Acta. Met., vo1. 22, 1974, p. 1065.

120. Y. Katz, Third International Congress on Fracture, Munich, W. Germany, Verein Deutscher Eisenhuttenleute, DUsseldorf, vol.V., April 1973.

121. M. H. Castro-Cedeno, M.S. Thesis, Department Materials Science and Engineering, University of California, Berkeley, February 1977.

122. J.H. Shively, R. F. Hehemann, and A. R. Troiano, Corrosion, vol. 22, 1966, p. 253. 

This report was done with support from the United States Energy Research and Development Administration. Any conclusions or opinions expressed in this report represent solely those of the author(s) and not necessarily those of The Regents of the University of California, the Lawrence Berkeley Laboratory or the United States Energy Research and Development Administration. 